NBER WORKING PAPER SERIES

\title{
RELATIONAL COSTS AND THE PRODUCTION OF SOCIAL CAPITAL: EVIDENCE FROM CARPOOLING
}

\author{
Kerwin Kofi Charles \\ Patrick Kline \\ Working Paper 9041 \\ http://www.nber.org/papers/w9041 \\ NATIONAL BUREAU OF ECONOMIC RESEARCH \\ 1050 Massachusetts Avenue \\ Cambridge, MA 02138 \\ July 2002
}

We thank Robert Axelrod, Rebecca Blank, John Bound, Charles Brown, Mary Corcoran, John Dinardo, Jeff Dominitz, Ronald Ehrenberg, Kevin Lang, Glenn Loury, Gary Solon, Melvin Stephens Jr., David Thatcher, and seminar participants at the University of Michigan, Northwestern University and Boston University for useful comments. The views expressed herein are those of the authors and not necessarily those of the National Bureau of Economic Research.

(C) 2002 by Kerwin Kofi Charles and Patrick Kline. All rights reserved. Short sections of text, not to exceed two paragraphs, may be quoted without explicit permission provided that full credit, including (C) notice, is given to the source. 
Relational Costs and the Production of Social Capital:

Evidence from Carpooling

Kerwin Kofi Charles and Patrick Kline

NBER Working Paper No. 9041

July 2002

JEL No. Z13

\begin{abstract}
This paper posits that individuals can more easily form social connections with persons of the same race. If true, the greater the incidence among his neighbors of persons of his race, the more likely an individual is to make neighborhood social capital connections, and the more likely he is to engage in activities which require it. The paper tests this idea using an indicator of individual social capital never previously studied: whether the person uses a carpool to get to work. We identify exogenous variation in adult neighborhood racial makeup arising from the racial makeup of the state in which the person was born in the year that he was born, and relate this exogenous portion of adult neighborhood racial composition to individual carpooling propensity using a TSLS approach. The results from this analysis, and from robustness tests which focus on neighborhoods with virtually identical racial distributions, show evidence of strong cross-racial relational difficulties, but interestingly, only for particular pairs of racial groups.
\end{abstract}

Kerwin Charles

408 Lorch Hall

Department of Economics and Ford School University of Michigan

611 Tappan Street

Ann Arbor, MI 48109

and NBER

kcharles@umich.edu
Patrick Kline

Department of Economics

University of Michigan

611 Tappan Street

Ann Arbor, MI 48109

klinep@umich.edu 


\section{Introduction}

Despite much recent work on the effects of social capital, relatively little is known about what factors determine if social capital exists in the first place. $\square_{\text {This }}$ paper studies the production of social capital. We present a simple model in which an individual's stock of social capital is formed out of the investments made in his separate pair-wise connections with other people. Investment in a particular pair-wise connection is easier if both persons share characteristics such as race which affect the ease, frequency and nature of social interaction. Thus, an individual's stock of neighborhood social capital should be increasing in the fraction of his neighbors who are of the same race. And, he should be more likely to engage in behaviors which require neighborhood social capital the more prevalent persons of his own race are among his neighbors. We test this idea using individual carpooling behavior as an indicator and find results which confirm the model's prediction.

Several things distinguish our work from the other work on social capital. First, most of the previous literature focuses on social capital measured at an aggregate level, such as the state or country. We argue that aggregate social capital is formed out of the different levels of social capital possessed by individuals. Thus, it is only by studying individual social capital, an emphasis Glaeser et al (2000) call an "economic approach to social capital", that we can learn how social capital at any level is determined.

Second, despite the individual focus, our work emphasizes social capital's fundamentally interactive nature. Thus, unlike standard human capital, for which an individual's investment decisions are affected only by his own characteristics, we argue that social capital investment is likely

\footnotetext{
${ }^{1}$ Seminal theoretical work on social capital include Loury (1977), Putnam (1993) and Coleman (1990). Arrow (1972) discusses how cooperation can lower transactions costs of economic activity. Becker and Murphy (2000) discuss the role of social capital in creating norms. Recent empirical pieces on social capital include Knack and Keefer, (1997), La Porta et al., (1997), Putnam, (1993), (1995), (2000). Glaeser et al (2000) discuss the relative sparseness of the literature on the production of social capital. See Durlauf (1999) and Portes and Landolt (1996) for criticisms of other aspects of work on social capital, including a critique of the common practice of adopting a functional definition for the phenomenon.

${ }^{2}$ See Putnam (1993), (1995), (2000); Knack and Keefer (1997); La Porta et al., (1997); Guiso et al., (2000); and Hall et al., (1999) for example.
} 
affected by how his characteristics relate to those of the other people in his social sphere. Previous studies of individual level social capital have not emphasized the importance of this interaction between own and community characteristics. On the one hand, work such as that by Glaeser et al (2000) models social capital as another type of human capital, determined by individual characteristics. At the other end, work by Alesina and LaFerrara (2000), and others, which relate individual indicators of social capital to measures of the overall distribution of community characteristics such as the level of community diversity, do not in general focus on the fact that community diversity will have different effects for different individuals.

Third, we use an indicator of social capital which has never previously been studied. Because social capital is not observed, the literature typically studies an outcome or behavior for which it can reasonably be presumed that those engaging in the behavior have more social capital than those who do not. We think that individual level carpooling is more likely to meet this condition than the most commonly used indicators in the previous literature: "trust" and "organizational membership."

"Trust" is usually determined from survey responses to questions about how much the respondent trusts others. These questions measure latent sentiments, and as such have been criticized by scholars who favor measurable behaviors over reports of unobservable beliefs. $\mathrm{B}$ Because of these problems, some researchers have used instead a survey-based measure of the different organizations to which people belong. 1 Belonging to an organization or a club is an action, and it is often a social

\footnotetext{
${ }^{3}$ See Fukuyama (1995), Guiso, Sapienza, and Zingales (2000), Knack and Keefer (1997), La Porta et al. (1997) and Putnam $(1993 ; 2000)$ for work using trust measures. An example of the type of question from which this information is derived is Knack and Keefer (1997), whose measure of trust is from the question: "Generally speaking would you say that most people can be trusted, or that you can't be too careful in dealing with people?" We are not the first to note the problem with trust measures. Putnam (1995) says that trust's centrality to social capital theory makes it ".. desirable to have strong behavioral indicators of trends in social trust or misanthropy. I have discovered no such behavioral measures." Also, Glaeser et al. (2000) find that survey questions on trust are only moderately correlated with an individual's trustworthiness.

${ }^{4}$ Most papers on social capital by economists in the U.S. use data from the same data source - the General Social Survey, or G.S.S. See DiPasquale and Glaeser, (1999), Maluccio, Haddad, and May (2000), Putnam (1993), (2000), Alesina and LaFerrara (2000) for recet examples.
} 
action, in that clubs bring people into contact with others. There may even be a connection between trust and organizational membership if, as Putnam (1995) argues, "people who join are people who trust." But there are reasons to be concerned about this measure as well, though these have rarely been emphasized in the literature.

For one thing, there are clubs which do not require that their members interact at all. And, interaction in a club need not occur among individuals in the particular sphere implicitly being studied. Neighborhood social capital is likely to be very poorly proxied by whether people belong to a college alumni club, since members of these clubs are likely scattered all over the country. The most important problem, though, is that people who belong to organizations may not have more social capital than people who do not, on average. This is because people may join organizations because the social capital they already have is low. People who join dating clubs are probably brought into contact with other people, raising their social capital. But, such people are not likely to have a large circle of friends and acquaintances. If they did, meeting people to date using their stock of social capital would not be at all difficult, and there would be no need to rely on the benefits of a formal club.

We eschew these measures in favor of carpooling as an indicator of neighborhood social capital for a number of reasons. Carpooling is an action and not a report of a latent sentiment. A carpool is a type of organization, but one whose members must interact. Unlike many clubs, which people can join without initially knowing any other members, carpoolers must know each other in order to organize their ride sharing activities. Carpoolers likely to trust each other to drive carefully, and to show up on time. Finally, because carpoolers tend to live in the same neighborhood, we can be explicit about the geographic sphere over which carpoolers' social capital operates.

\footnotetext{
${ }^{5}$ That carpoolers live in the same neighborhood is confirmed by a survey of commuting behavior in the California Bay Area, which indicates that carpoolers spend an average of only 4.8 minutes picking up other passengers (DOT (1996)).
} 
Carpooling is also an outcome of independent interest. Carpool lanes are an increasingly popular sight on the nation's roadways, as communities attempt to induce more of this behavior. Carpooling's potential ability to reduce pollution and traffic congestion, in addition to how it can lower spatial mismatch problems between (particularly poor) workers and the jobs to which they aspire, are all reasons why a better understanding of the determinants of this behavior is of substantial public policy interest.

The empirical work relates individual car pooling propensity to variables measuring the interaction between own race and neighborhood racial characteristics. The fourth distinguishing trait of our analysis is the fact that we exploit plausibly exogenous variation in neighborhood racial composition using information on the person's state of birth as instrumental variables.

The next section presents a very simple theoretical model which introduces key concepts and sets the stage for the subsequent empirical analysis. Section 3 discusses the basic empirical strategy. Section 4 discusses the data. Section 5 discusses exogenous variation in neighborhood composition. Results are presented in Section 6, and Section 7 concludes

\section{Theoretical Framework}

\section{Social Capital Production}

We define social capital as the commodity which individuals use in non-market, social interactions to extract valuable resources. Thus, people might use their social capital to get advice, companionship, financial resources, or assistance with various life tasks such as daycare for children or help in getting to work. Let $s_{i j}, s_{i j} \geq 0$, be the social capital which an individual $i$ possesses for exclusive use in social interaction with some different person $j$. The size of $s_{i j}$ describes how much $i$ can get from $j$ in social interaction and will, in general, differ from what he can get from a different individual. We argue that all forms of social capital ultimately derive from these pair-wise connections. 
Rather than the innumerable pair-wise social capital connection that an individual $i$ possesses, we could focus instead on his social capital stock, as measured against a particular universe, $U$. A simple measure of this individual stock is $S_{i}^{U}=\sum_{j} s_{i j}, j \in U$. Another is $\phi_{i}^{U}$, which is a binary variable which equals 1 if the person has at least one non-zero pair-wise social capital connection with another person in the universe $U$. If $U$ is "the neighborhood", then both $S_{i}^{U}$ and $\phi_{i}^{U}$ are measures of a person's "neighborhood social capital stock."

This way of thinking about social capital highlights that a person with a very low social capital stock when assessed against a given universe, may have a high stock when measured against another. Different types of social capital stocks are probably of differential importance in different circumstances. An individual's global social capital may be important when he desires advice about where to send his son to college, while his neighborhood social capital is probably more important when he wishes that someone keep an eye on his house while he is vacationing.

We assume that the social capital connection between two individuals, $s_{i j}$, is increasing in social capital investments made by each person in the pair. Two types of costs and benefits characterize social capital investments. One set, which we call autonomous, are not the focus of this paper. These are benefits and costs which affect an individual's incentive to make social capital pairwise investments, irrespective of the other person with whom the connection is being made. Thus, older people may have smaller benefits from investment, since they have a smaller horizon over which to recoup any benefits from investment. We focus on the benefits and costs associated with investment in pair-wise social capital which are relational. These depend on whether the other person in the pair for which the pairwise investment is being made has particular characteristics in common

\footnotetext{
${ }^{6}$ Our framework readily captures social capital measured at the aggregate, or community, level. For a given region or community, aggregate global social capital is just the aggregation of the all the individual stocks of global social capital of the people who live in that community.
} 
with the person making the investment. We focus on the relational trait of race in this paper, and study neighborhood social capital.

Consider a one-period model in which individuals are each endowed with a single unit of time. This time endowment is used for two things: to invest in social capital connections with people in the individual's neighborhood, and to engage in some other alternative productive activity, $A \mathrm{Q}^{\mathrm{Q}} \mathrm{At}$ the start of every period, individuals choose how much time, $t_{i A}$, to devote to the alternative activity. They then randomly encounter a person from their neighborhood and use the remaining time $t_{s}=1-t_{i A}$ to invest in social capital connections with them. At the end of this second investment, payoffs are received.

For simplicity assume that the gain from one unit's time investment in both the alternative activity and from human capital investment be the same. Let the cost of investing in the alternative activity be the convex function $g_{a}\left(t_{a}\right)$. Let there be no autonomous costs of social capital investment, but let the relational cost of social capital investment with someone of the same race be $R C_{\text {low }}\left(t_{s}\right)$, and $R C_{\text {high }}\left(t_{s}\right)$ when investing with someone of a different race be, where $R C_{\text {high }}^{\prime}\left(t_{s}\right)>R C_{\text {low }}^{\prime}\left(t_{s}\right)$.

In this simple setup is follows straightforwardly that a person invests in the alternative activity up to the point that

$$
g^{\prime}\left(t_{a}\right)=\rho_{L} R C_{\text {low }}^{\prime}\left(t_{s}\right)+\rho_{H} R C_{\text {high }}^{\prime}\left(t_{s}\right)
$$

where $\rho_{L}$ and $\rho_{H}$ represent the probability that a person encountered in a random meeting will be of the same or different race, respectively, and $\rho_{L}+\rho_{H}=1$.

For a person of race $R$, expression (1) can be re-written

$$
g^{\prime}\left(t_{a}\right)=\pi_{i N}^{R}\left[R C_{\text {low }}^{\prime}\left(t_{s}\right)-R C_{\text {high }}^{\prime}\left(t_{s}\right)\right]+R C_{\text {high }}^{\prime}\left(t_{s}\right)
$$

\footnotetext{
${ }^{7}$ This other activity could be time spent working, or time spent investing in another type of social capital, perhaps with people outside of the neighborhood, or time spent alone reading or watching television. The exact nature of the alternative activity is not essential.
} 
where $\pi_{i N}^{R}$ is the fraction of the person's neighborhood which is also race $R$ since $\pi_{i N}^{R}$ measures the likelihood that a neighbor whom he randomly meets will be of the same race. Since $g^{\prime}\left(t_{a}\right)>0$, and since $R C_{\text {high }}^{\prime}\left(t_{s}\right)>R C_{\text {low }}^{\prime}\left(t_{s}\right)$, expression 2 indicates that people should devote less time to the alternative activity, and thus more time to social capital investment, the greater the incidence of people of their own race in their neighborhood. This means that a person's stock of neighborhood social capital should be rising with the fraction of his neighbors who are of his race.

Denote the different races $R=j, k, l$.. Let $\phi_{i N}^{j}$, the stock of social capital held by person $i$ of race $j$ in living in neighborhood $N$, be a function of racial distribution in his neighborhood, or

$$
\phi_{i N}^{j}=\sum_{R} \beta_{j R} \pi_{i N}^{R}
$$

where $\pi_{i N}^{R}$ is the fraction of the neighborhood of race $R, \sum_{R} \pi_{i N}^{R}=1$, and the terms $\beta_{j R}$ are coefficients. Since by condition (2) increasing the incidence of a person's own race among his neighbors by lowering the incidence of any other race, raises his neighborhood social capital,

$$
\beta_{j j}>\beta_{j k} \text { and } \beta_{k k}>\beta_{k j}
$$

for any two races $j \neq k$. These conditions together imply that

$$
\left(\beta_{j j}-\beta_{j k}\right)>\left(\beta_{k j}-\beta_{k k}\right)
$$

Condition (5) implies that if there is a neighborhood in which the incidence of race $j$ people relative to race $k$ people is higher than in some other neighborhood, social capital among race $j$ people relative to race $k$ people is higher in the first neighborhood. Testing this prediction for different

\footnotetext{
${ }^{8}$ This result follows trivially when the person with whom a social capital connection is to be made is encountered at random. One can envision more complicated, and more realistic, scenarios in which people seek out neighbors who share relational their traits. The basic result presented here should still hold in more complicated models because the search costs associated with finding people with whom one has low relational costs should be decreasing in the prevalence of such people in the neighborhood.
} 
racial pairs $j$ and $k$ is the focus on the empirical work which follows. Unfortunately, because social capital, $\phi_{i N}^{R}$, is not observed, (5) cannot be tested directly. However, we have argued that there is $a$ priori reason to suppose that an individual's carpooling propensity covaries positively with his stock neighborhood social capital. We propose to use this fact to indirectly test (5).

\section{Empirical Strategy}

The probability that an individual carpools to work depends, in general, on individual level characteristics, such as his income and how far he lives from his job; characteristics of his neighborhood, such as whether it is served by public transportation or is well illuminated; and his level of neighborhood social capital. The carpooling propensity of a person of race $j$ living in a neighborhood $N=a, b, c \ldots$ can thus be written

$$
C P_{i N}^{j}=\alpha \phi_{i N}^{j}+v_{N}+u_{i N}^{j}
$$

where $\phi_{i N}^{j}$ is the person's neighborhood social capital, $v_{N}$ are characteristics of the neighborhood, $u_{i N}^{j}$ are individual-level determinants of carpooling, and the constant $\alpha>0$. Substituting expression (3). (6) can be re-written

$$
C P_{i N}^{j}=\alpha\left(\sum_{R} \beta_{j R} \pi_{i N}^{R}\right)+v_{N}+u_{i N}^{j}
$$

The difference in carpooling propensity between two persons of race $j$ living in two neighborhoods $a$ and $b$ relative to the same difference for two persons of race $k$ living in the two neighborhoods is

$$
\Delta^{j}\left(C P_{i N}\right)-\Delta^{k}\left(C P_{i N}\right)=\alpha\left[\Delta^{j}\left(\sum_{R} \beta_{m R} \pi_{i N}^{R}\right)-\Delta^{k}\left(\sum_{R} \beta_{n R} \pi_{i N}^{R}\right)\right]+\left[\Delta^{j}\left(u_{i N}\right)-\Delta^{k}\left(u_{i N}\right)\right],
$$

where $\Delta^{R}(x)$ denotes the difference in the variable $x$ between two individuals of race $R$ living in the two different neighborhoods. Notice that in (8), differences in neighborhood-level factors, 
common to all people living in the neighborhoods, have been differenced out. Making use of the fact that $\Delta^{j}\left(\pi_{i N}^{R}\right)=\Delta^{k}\left(\pi_{i N}^{R}\right)$, plus the fact that $\sum_{R} \pi_{i N}^{R}=1$, expression 8$)$ can be written

$$
\begin{aligned}
\alpha\left[\left(\beta_{j j}-\beta_{k j}\right)\right. & \left.\Delta\left(\pi_{i N}^{j}\right)+\left(\beta_{j k}-\beta_{k k}\right) \Delta\left(\pi_{i N}^{k}\right)+\sum_{R \neq j, k}\left(\beta_{j R}-\beta_{k R}\right) \Delta\left(\pi_{i N}^{R}\right)\right] \\
+ & {\left[\Delta^{j}\left(u_{i N}\right)-\Delta^{k}\left(u_{i N}\right)\right] }
\end{aligned}
$$

Expression (9) suggests that regression analysis could be used on double difference estimates of the form of (9) to test proposition (5). In particular, if the relative difference in carpooling between race $j$ and race $k$ people living in two neighborhoods, were regressed on the terms summarizing the differences in the incidence of the different races across those neighborhoods, the difference in the estimated coefficients on the terms $\Delta\left(\pi_{i N}^{j}\right)$ and $\Delta\left(\pi_{i N}^{k}\right)$ would be a test of

A more tractable method of estimating the relative difference model is with the following regression specification in the case where there are only three races - Whites $(W)$, Blacks $(B)$ and Hispanics $(H)$ :

$$
\begin{gathered}
C P_{i N}=\Gamma X+\delta_{s} s+\alpha_{W} W_{i}+\alpha_{B} B_{i}+\lambda_{W} \pi_{i N}^{W}+\lambda_{B} \pi_{i N}^{B}+ \\
\gamma_{W W}\left(W_{i} * \pi_{i N}^{W}\right)+\gamma_{W B}\left(W_{i} * \pi_{i N}^{B}\right)+\gamma_{B W}\left(B_{i} * \pi_{i N}^{W}\right)+\gamma_{B B}\left(B_{i} * \pi_{i N}^{B}\right)+\varepsilon_{i N s}
\end{gathered}
$$

In (10) $C P_{i N}$ measures whether individual carpools to work, and $\varepsilon_{i}$ is an error term. The vector $X$ is a set of individual and neighborhood level observable determinants of carpooling, $s$ is a vector of state fixed effects corresponding to the state in which the person lives is found. The binary variables $W_{i}$ and $B_{i}$ indicate whether the person is White or Black, with Hispanic being the excluded race. The expressions $\pi_{i N}^{W}$ and $\pi_{i N}^{B}$ measure the fraction of people in person $i^{\prime} s$ neighborhood who are White, and the fraction who are Black. The fraction Hispanic is excluded. If (5) holds, then in regression (10) $\left(\gamma_{W W}-\gamma_{B W}\right)-\left(\gamma_{W B}-\gamma_{B B}\right)>0, \gamma_{W W}>0$, and $\gamma_{B B}>0$. To see this, notice that the coefficient $\gamma_{B B}$, 
for example, equals $\left(\beta_{B B}-\beta_{H B}\right)-\left(\beta_{B H}-\beta_{H H}\right)$. Extensions to the case of more than 3 races is straightforward and condition (5) can thus be indirectly tested with results from (10)

In (10), the effect of unobserved neighborhood factors which affect persons of all races equally is accounted for. Yet, O.L.S. estimates may still not yield unbiased estimates of the parameters of interest if the racial makeup of the neighborhoods people choose to live is related to latent determinants of their carpooling behavior. For example, suppose that certain neighborhoods have clean, well illuminated bus stops. Then, workers with unreliable cars would systematically sort into such neighborhoods, confident that if their car failed they could take the bus. Now suppose that only blacks (though not all blacks) have unreliable cars. Then because of sorting, neighborhoods which turned out to be relatively more black would have relatively more people with bad cars. If having a bad car made people not only more likely to take a bus, but also more likely to seek out others in their neighborhood with whom to share a ride, regression 110 would find that blacks were relatively more likely to carpool in neighborhoods which were relatively more black. But this would have nothing to do blacks having relational costs with whites. In the empirical work below, we account for the possible endogeneity of the racial makeup of people's neighborhoods using an Instrumental Variables (IV) and Two Stage Least Squares (TSLS) technique, which we discuss in detail after a brief description of the data .

\section{Data}

The individual level data in the paper are drawn from the 1\% IPUMS Unweighted Sample of the 1990 United States Census. We restrict attention to working men aged $18-64 .{ }^{0}$ The Journey to Work portion of the 1990 Census asked working persons age 16 and above whether they usually traveled to work by car, truck, or van. If so, they were then asked how many people usually drove to

\footnotetext{
${ }^{9} \mathrm{We}$ focus on adult men because of their very high level of labor force participation.
} 
work in the car, truck, or van with them. If the person was driven to work by someone who then drove back home or to a non-work destination they were instructed to report "drove alone."

Strictly speaking a "carpooler" would be anyone who usually went to work by car with at least one other person. However, because we wish to be reasonably sure that the at least one rider in the car is someone from outside the person's household, most of the work below will say that someone carpools to work when he travels regularly with at least two other persons to work by car. All of the regressions also control for family size and family status, further ensuring that any effects we document are from carpooling behavior with people from the neighborhood and not from the household.

The IPUMS data provides detailed information about wages, occupation and industry, time to work, and the number of cars available in the household- all likely important determinants of

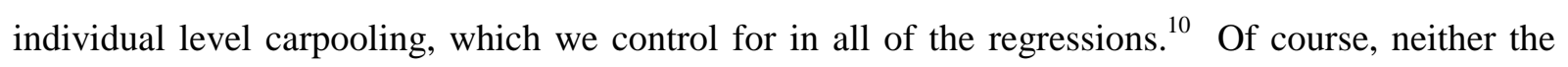
IPUMS data nor any other data source provides a completely satisfactory description of an individual's "neighborhood." The IPUMS data provides three pieces of information about respondents' spatial location - the man's state of residence; his metropolitan area (MA), and a geographic region called a Public Use Microdata Area (PUMA) in which the man resides. We eschew the MA in favor of the PUMA mainly because PUMAs are much smaller than MAs, and therefore much more closely connected to conventional notions of a neighborhood. ${ }^{\text {Also, not every IPUMS }}$ respondent is attached to an MA, whereas every person is matched to a PUM. ${ }^{2}$ Finally, unlike MAs,

\footnotetext{
${ }^{10}$ Additional details about these variables may be found in the Data Appendix.

${ }^{11}$ The median size of an MA is 229,290 people (2,932,707 acres) while the median size of a PUMA is only 123,936 people (667,440 acres).

${ }^{12}$ The Census defines an MA as a group of adjacent communities with a large population nucleus that have a high degree of economic and social integration. Each MA must contain either a Census designated "place" (i.e. city) with a Minimum population of 50,000 or a Census designated Urbanized Area with a population of at least 100,000. Because many areas do not meet these requirements there are only 342 MAs nationwide. These MAs hold about $77 \%$ of the total population of the United States but only about $16.5 \%$ of the total land area.
} 
PUMAs (from the state sample) do not cross state boundaries, so it is possible to account for unobserved state fixed effects.

Data on the aggregate characteristics of PUMA's are constructed from an additional data source. The Census collects aggregate information about more than 200,000 geographic units, called "block groups," out of which most other levels of aggregate census geography are constructed. These data for 1990 are reported in the 1990 Census STF3 tables. By and large, block groups do not cross PUMAs boundaries, so we calculate mean aggregate PUMA-wide characteristics from the totals reported in the STF3 tables of block groups within that PUMA. ${ }^{13}$ When data from the IPUMS is merged with the PUMA data, we have a sample consisting of an observation for each working man in the IPUMS sample, and aggregate information - including the racial distribution- of the PUMA in which that man resides. Our primary data set has observations on more than half a million working men between 18 and 64 drawn from 1726 PUMAs, covering every state and the District of Columbia.

Race is divided into five groups: White, Black, Asian-Pacific, Hispanic, and Other. White, Black, and Asian were defined according to the usual census criteria; the definition of Hispanic and Other, however, require some extra discussion. The census does not officially define Hispanic as a race. Individuals who fill out the census are asked to choose from five categories: White, Black, Asian, Native American, and Other. In a separate question they are asked whether they are of Hispanic Origin or not. In order to avoid confusing race with ethnicity, we classify Hispanics as individuals who claimed to be neither White, Black, Asian, nor Native American, but who reported being of Hispanic origin. Because of their small population shares, we combined Native Americans and Non-Hispanic Others into a single category, henceforth referred to as Other. ${ }^{14}$

\footnotetext{
${ }^{13}$ Census block group data was matched with PUMA identifier using CIESIN's online Master Area Block Level Equivalency engine at http://plue.sedac.ciesin.org/plue/geocorr/.

${ }^{14} \mathrm{We}$ ran models in which Hispanics were defined as any persons who claimed to be of Hispanic origin, irrespective of the race they reported. The results from these models were qualitatively very similar, if not a little stronger, than the results we present here.
} 
Table 1 lists the means and standard deviations for carpooling and for the large number of control variables from the matched IPUMS sample. Under our definition of race, Whites comprise $83.6 \%$ of the individual observations and PUMA's are, on average, $81.3 \%$, white. Hispanics only comprise $3.9 \%$ of the individual observations and the mean percent Hispanic of the PUMAs is $3.7 \%$. This distribution is somewhat different from other definitions of Hispanic and White, and derives from our desire to distinguish between race and ancestry or ethnicity.

The means and standard deviations of the other key variables are presented in the table. These means, except for individual level carpooling, should be very familiar. The table shows that $13.4 \%$ of working men travel to work by car with at least one other person. Under our preferred, but much more restrictive definition, in which carpooling is said to occur when there are at least 2 other people in the car, the frequency of carpooling falls to $3.1 \%$.

Table 2 summarizes carpooling for each racial group. Hispanics carpool the most and Whites the least, irrespective of the definition of carpooling. Indeed, Hispanics tend to carpool about four times as much as Whites. The results in this table indicate that different races may have different propensities to carpool. Whether these differences are systematically related to the racial makeup of the neighborhoods in which people live in the manner suggested by the relational cost argument outlined earlier is the focus of the work which follows.

In the next section, we discuss how we identify exogenous variation in the racial distribution of the PUMAs in which individuals live. That variation will be exploited in the later analysis to isolate the causal effects of racial distributions of neighborhoods on individuals' carpooling propensities.

\section{Exogenous Variation in Neighborhood Racial Distribution}

In the empirical work, we instrument for neighborhood racial distribution because of concern that these variables are endogenous with respect to individuals' carpooling propensities. Our 
instrumental variables approach is motivated by two facts. First, most adult Americans live relatively close to where they were born. Second, there is dramatic spatial autocorrelation in the racial distributions of different neighborhoods. That is, neighborhoods which are close together spatially tend to be very similar racially. Putting these two facts together, part of the racial distribution of the neighborhood a person lives in as an adult is plausibly exogenous to his carpooling propensity as an adult. The exogenous part is that portion of his neighborhood racial distribution which derives from the racial makeup of the state and year in which he was born. Variables summarizing these state of birth / year of birth racial distributions are the instruments used in the later analysis.

We begin with evidence about people's tendency to live in a neighborhood close to the place they were born. We present results for people born in Alabama, Iowa, Massachusetts, and California choosing one state each from the South, Midwest, Northeast and West. The results for other states of birth are similar to those for these four states, so any other set of states would have made the same illustrative point. From the IPUMS we calculate the number of people born in the state in question who, in 1990, live in each PUMA in the U.S. The graphs plot how this number for each PUMA deviates from the national mean across all PUMAs.

Each of the graphs makes the same essential points. First, adult Americans are most likely to live in PUMAs in the state where they were born. For example, the number of people born in Alabama who make PUMAs in Alabama their homes as adults is more than three standard deviations above the number who live in any other PUMA. The same pattern is evident for persons born in other states. Second, Americans do move out of the state where they were born, but when they do, tend to move to PUMAs very close to their state of birth, and rarely to PUMAs far away. Each graph shows that, apart from those in the state of birth, the PUMAs which are next most likely to be a person's home as an adult are those which directly adjoin the birth state. This basic pattern holds despite the fact that disproportionate number of movers go to PUMAs in Florida and California, probably 
because these are popular retirement destinations. And, it is true even for a state like Iowa, from which a relatively large fraction of native Iowans appear to move.

Because we have drawn these graphs in terms of standard deviations, they can be viewed as representing a simple statistical estimate of the probability that a person born in a given state will live as an adult into some particular PUMA. If where people were born had no effect on where they ended up as adults, then the entire graph would be the same color, and it would be impossible to tell what state of birth was being discussed just by looking at the graph. Instead, the figures show dramatically that the likelihood that a person lives in a given PUMA is a decreasing function of the distance of that PUMA from the state where he was born.

The second fact which underlies our instrumental variables strategy is that PUMAs which are close together tend to be very similar racially. To illustrate this point, we graph how the fraction of each PUMA which is of a given race compares to fraction of the national population which is that race. We do this for the four largest racial groups in the country - Whites, Blacks, Hispanics and Asians.

The figures show that PUMAs which have more racial minorities than the average national representation of groups tend to be bunched very closely together. For Blacks, apart from a very few isolated pockets in the Midwest, all of the PUMAs with black representations two or three standard deviations above the national mean are found in a band of cutting through the South and Southeast. For Hispanics, apart from a pocket in southern Florida, PUMAs with more than the national average of Hispanics are found in mainly in the Southwest and particular parts of the far West. There are a few PUMAs with high Asians populations, relative to the national average, in the East and Midwest but for the most part heavily Asian PUMAs are in the far West. The figure for Whites is consistent with the patterns for the other groups. Most PUMAs have approximately the same fraction of White residents, except for the "ethnic enclaves" described above, where the incidence of Whites is lower than the national average. One enclave not evident from the other graphs is the one in South Dakota, 
where the fraction of Whites is lower than the national mean probably because of the large number of Native Americans who live there.

The graphs show not only tremendous "bunching" of the neighborhoods, but there is also evidence of a "smooth gradient," in the sense that a small change in geographic position (in any direction) tends to create a small change in racial distribution. For the most part, a very heavily Black or Hispanic PUMA is very rarely found directly next to one which is very low in the incidence of these groups.

This distributional continuity combined with the fact that adults tend live close to where they were born means that the racial distribution of the neighborhood that a person lives in as an adult is a function of the state in which he was born. Specifically, a determinant of a person's neighborhood racial make-up should be the racial distribution of the state and year in which he was born. Moreover, since the racial makeup of a person's birth state is plausibly exogenous with respect to his subsequent carpooling propensity, these measures are very good instruments for the neighborhood shares in the regressions (10) we use to test the relational cost idea.

To construct the instrumental variables for Two Stage Least Squares (TSLS) analysis we use census information on the historical composition of the fifty United States and the District of Columbia over time. Since the oldest person in the 1990 sample is 64 and the youngest is 18, it is necessary to obtain information on state's racial distributions between the years 1926-1972. Unfortunately, this information does not exist for each individual year, so we estimate each individual's birthplace distribution using the distribution in their state of birth at the time of the nearest decennial census.

Data for the years 1930-1960 was obtained from the "United States Historical Census Data Browser" at the University of Virginia. ${ }^{15}$ Values for 1970 were constructed as sample means from the

\footnotetext{
${ }^{15}$ This is an online service available at http://fisher.lib.virginia.edu/census/. Some values for some states in some years were missing or invalid. Where possible we obtained estimates for these missing values using the sample mean of the equivalent IPUMS variable in that year.
} 
1970 IPUMS. Because the definitions of race used in the census have changed over time, our historical racial composition variables are not as extensive as our measures for 1990. The fraction of states which were Asian-Pacific or Hispanic cannot be determined in certain Census years. As a result, we drew three values from the data sources for each state/decade combination: the percent of the state that was White in that decade, the percent of the state that was Black in that decade, and the percent of the state that was Foreign-born in that decade. Percent Black and Percent Foreign-born were measured fairly consistently over time. Percent White is not measured the same way in each decade, with some decades explicitly lumping many Hispanics into the category. Because the percent of any state that is White is almost always very large, we believe that any distortions in the level of the variable due to changes in definition are likely to be small.

How does the racial distribution of the person's state of birth in the year that he was born correlate with the racial distribution of the neighborhood he lives in as an adult? Table 3 reports the results of various regressions in which each of the racial percentages in a person's neighborhood is regressed against terms summarizing the racial makeup of his state of birth in his year of birth. The latter terms are instruments in the TSLS regression performed below, so these regression results may be read as summarizing the "first stage" analysis.

Counting all of the terms in equation (10) which involve any measure of a percent of a neighborhood which is of a certain race, there are 20 endogenous variables in our analysis when we separate races into Blacks, Whites, Hispanics, Asians, and Others. We use thirty instruments: three terms summarizing the fraction of the state/year of birth cell which is Black, White, and Foreign Born; the interactions between these terms; the interactions between the person's own race and the three percent terms; and the interactions between person's own race and the interacted percent terms. We run separate regressions for the each endogenous variable, using all 30 instruments, and all of the other individual and neighborhood level controls used in the analysis. 
We only present first stage results for the four regressions of the fraction of a person's adult neighborhood which is Black, the fraction White, the fraction Hispanic, and the fraction Asian, and not for the different interaction terms, both to conserve space and because the results are qualitatively similar for other variables. We summarize the effect of the instruments on the variables in question using the partial $R$-squared of a regression in which the endogenous variables are regressed on the instruments, after the effect of all of the other individual and aggregate controls have been netted out of these variables. We also present the $F$-statistics which test the joint significance of the instruments on the neighborhood racial shares, in a regression with all of the other controls. As has been argued by Bound, Jaeger and Baker (1995) and Staiger and Stock (1997), the size of these first stage $F$-statistics is a good indicator of the strength of the instruments. Importantly, in all of these first stage regressions, standard errors are corrected for clustering at the level of the birth state / year of birth. Hoxby and Paserman (1998) show that the failure to cluster in contexts such as this can lead to dramatically incorrect standard errors.

Table 3 shows that the measures summarizing the racial distribution in an individual's state of birth in the year that he was born are very strong predictors of the each of the four racial shares of the neighborhood that he lives in as an adult. The partial $R$-squared statistics for the excluded instruments range between a low of 0.0009 for the fraction of the neighborhood which is Asian to 0.0045 for the fraction of the neighborhood which is Black. These are very large. More dramatically are the first stage $F$-statistics which are all around 10 , with p-values of 0 .

Overall, this analysis formally shows what the earlier graphs indicated: the state/year of birth neighborhood racial characteristics are strong predictors for the racial makeup of the neighborhood a person lives in as an adult. They are thus ideal instruments for the potentially endogenous adult neighborhood racial distribution in a two stage least squares (TSLS) analysis performed on (10) The results forthcoming from such an analysis measures the causal effect of neighborhood racial 
distribution on carpooling propensity, thereby providing a test of the relational cost argument presented above.

\section{Results}

\section{A. Base Results}

Before assessing how neighborhood composition affects carpooling propensity, we present the results of a base specification in which carpooling is related to individual and community level characteristics from the IPUMS. We present these results because the effect of the various controls, which may be of independent interest, are not presented in later tables. 6 All of the later models controls for all of the variables shown in this regression.

Table 4 presents linear probability results for two measures of carpooling: a binary variable indicating that the person traveled to work with at least one other person, and one indicating that he traveled with two or more people. Because we want to study carpooling with people outside of the household, all of the later work focuses on the more restrictive definition. The standard errors reported in the table allow for clustering within each neighborhood, and for heteroscedasticity.

The results for this base specification indicate that younger people are more likely to carpool, as are those who live in large households and those who are married. Homeowners are more likely to carpool and, not surprisingly, the likelihood of carpooling varies inversely with the number of automobiles in the household. We relate carpooling to a quadratic in annual earnings. The looser definition finds that carpooling is initially rising then falling with earnings. However, when carpooling is defined as the presence of two or more riders, the quadratic effect vanishes. Overall, it appears that high earning persons do not carpool. Consistent with this result, the results show that as completed schooling rises, carpooling probability falls. Recipients of bachelor's degrees carpool less

\footnotetext{
${ }^{16}$ See the Data Appendix for a detailed description of these variables and our reasons for including them.
} 
than those with just high school degrees, but receiving more education than a bachelor's makes one more likely to carpool.

Since the Census has no direct measure of linear distance to work, we use whether an individual works in the same PUMA in which he lives and how long it takes to get to work as proxies for distance. Consistent with the fact that the potential savings in effort and resources from carpooling increase with trip size, we find that travel time has a very strong positive effect on carpooling. The strong effect of working in the same PUMA in which he lives is an additional estimate of this distance effect.

The base specification includes a rich vector of geographic controls to account for the fact that social interaction and commuting behavior might be qualitatively different in urban areas than in other places. Not only will factors like the availability of public transportation vary with urbanization, but having lots of people nearby makes interaction less costly. ${ }^{17}$ Furthermore traffic patterns, as well as available public transportation services likely differ between cities and suburbs and rural areas. If certain populations such as Blacks and Hispanics are more urbanized on average than Whites, failure to control for these effects could bias the estimated effects for the variables of main interest in the subsequent regressions. There is no single, ideal measure of urbanization, so we use a variety of possible geographic controls.

The results show that PUMA Population Density has a negative effect on carpooling. This may be because people in denser areas are more likely to use public transportation. However, the indicator variable for living in an urbanized area is positively related to carpooling (especially in the more restrictive definitions of carpooling). Since this dummy is a weaker test of urbanization and is really just a contrast to being rural, this result may merely indicate that carpooling is most prevalent in the suburbs. This is consistent with the spatial organization of most major metropolitan areas, whereby jobs are found in an inner core and large portions of the workforce reside in the suburbs. If

\footnotetext{
${ }^{17}$ Empirical studies by Festinger et al. (1950) and Glaeser and Sacerdote (2000) seem to support this notion.
} 
suburban workers have longer commutes, as shown above, the returns to carpooling should increase. Suburban residents may also face more direct incentives to carpool to urban cores in the form of federal highways and High Occupancy Vehicle (HOV) lanes that have minimum passenger requirements.

A particularly noteworthy set of controls in the base specification are those for for individuals' industry and occupation, and for industry and occupation affiliation of workers in the neighborhood. ${ }^{18}$ To the extent that the distribution of occupation and industries among the workers in a neighborhood are related to the racial distribution in that neighborhood, failure to control for both own and community level industry and occupation may lead us to incorrectly attribute any effects found for neighborhood racial distribution to social capital, rather than to the fact that people of the same race are simply going to the same place when they go to work and are thus more likely to carpool. The large number of industry and occupation effects, at both the individual and community level, makes it difficult to summarize the effect of these variables on carpooling. We find that most of the estimated effects are strongly statistically significant. Their inclusion in all of the regressions raises our confidence that any effect we find for the racial composition of communities, above and beyond the occupation distribution in those communities, is truly a measure of a social capital effect, rather than the unmeasured propensity of people from the same race to be more likely to be going to the same workplace. We also control for the average time to work among workers in the community as an additional guard against this concern.

\section{B. OLS Estimates of Effect of Neighborhood Racial Composition on Carpooling Probability}

Having examined the base determinants of carpooling, we turn to the paper's central hypothesis captured in conditions (5) and (8), if race is a relational trait, then carpooling for persons of a one race relative to another should be higher when the neighborhood incidence of the first race is

\footnotetext{
${ }^{18}$ These estimated effects are presented in Appendix Table 1.
} 
higher relative to the second. In this section, we present the results of this relative difference test when the potential endogeneity of neighborhood racial makeup is not accounted for. Table 5 presents simple linear O.L.S. estimates of the effect of neighborhood composition on carpooling. Henceforth we focus only on the more restrictive carpooling definition - whether the person rides to work with at least two other people. The table presents the estimated difference in difference estimate for different pairs of races. 19 The regressions which yield these estimates are linear probability models, with standard errors clustered by PUMA and corrected for heteroskedasticity.

The results from three regressions are presented in the table. The regression in the first column only controls for individual variables from the base specification shown earlier. The second column adds the PUMA level variables. State fixed effects are added in the last column.

The results in the first column show that when only individual variables are controlled for, the relative racial difference in carpooling propensity with respect to the neighborhood racial makeup is as predicted by the model, so long as one of the racial groups is not Whites. Blacks carpool relatively more than Hispanics when neighborhoods are relatively more Black than Hispanic; Asians carpool relatively more than Hispanics when the neighborhoods are relatively more Asian than Hispanic; and Blacks carpool relatively more than Asians in neighborhoods relatively more Black than Asian. These three results are exactly as predicted by the model. However, for Whites, only the relative difference with respect to Asians is of the sign consistent with the model. The results for Whites and Blacks and for Whites and Hispanics are not statistically significant.

Adding the controls for PUMA level variables in the second column lowers all of the estimated relative differences. More importantly, the results are essentially the same as those in the first column. Again, no relative difference involving Whites is statistically significant. The regression in the last column adds state fixed effects. The relative racial differences in these estimates are from

\footnotetext{
${ }^{19}$ The relevant tests are straightforward $t$-tests, since the functions are linear combinations of OLS coefficients.
} 
comparisons across PUMAs in the same state. The table shows that these results are basically the same as those in the other columns.

If we could be certain that individuals' neighborhood racial distributions were exogenous, the estimates in Table 5 would suggest that relational costs affected only some cross-racial relationships, and not others. This would be an interesting finding, if true. However, if there is a systematic relationship between the racial make-up of the neighborhoods that people choose to live in, and unobserved determinants of carpooling behavior, then the estimated effects for the racial composition of neighborhoods on carpooling will be biased and inferences based on such estimates invalid.

Below, we estimate the model using Two Stage Least Squares (TSLS) models which exploit plausibly exogenous variation in neighborhood racial makeup.

\section{TSLS Estimates of Effect of Neighborhood Racial Composition on Carpooling Probability}

In Section 5, we demonstrated that people tend to live as adults in PUMAs either in or very close to the state in which they were born. We showed as well that the racial makeup of neighborhoods in the United States is very spatially correlated. These two facts suggested, and the tests we performed confirmed, that variables summarizing the racial makeup of the state in which a person was born in the year that he was born strongly affect the racial makeup of the PUMA he lives in as an adult. Since these state of birth / year of birth racial composition variables were determined before a man was born, they are plausibly uncorrelated with his adult carpooling propensity, except insofar as they determine the racial makeup of the neighborhood he lives in as an adult. The TSLS estimates in this section use only this exogenous portion of adult neighborhood racial shares to estimate the effects of interest.

Table 6 presents estimates of the relative difference effects, from a TSLS model in which the state of birth / year of birth racial composition variables are used as instruments for the adult PUMA racial distribution variables. We present three sets of results. In the first column, apart from the 
endogenous neighborhood racial shares, the model has only individual level variables. The regression in the second column has both PUMA and individual level variables. The one in the last column adds state fixed effects.

Whereas the OLS results found no relative difference in the carpooling rates of Whites relative to other races when the Whites constituted relatively more of neighborhoods, the TSLS results find that this effect is positive and strongly statistically significant for the White-Hispanic relative difference in every specification. The White-Black difference is positive but not significant when the model controls only for individual level variables. However, when aggregate PUMA controls and state fixed effects are added in turn, this relative difference too is positive and strongly statistically significant. These results are strong evidence that Whites face relational difficulties when interacting with Blacks and Hispanics, and vice versa.

Interestingly, the TSLS regressions suggests that there is no relational difficulty between Whites and Asians, as evidenced by the fact in none of the specifications are the relative carpooling rates of people from these races affected by exogenous variation in their relative presence in a neighborhood. To some extent, the same is true for the Black-Hispanic relative carpooling differences. A positive relative difference is found in the specification with only individual level controls, but the effect is not significant once aggregate neighborhood variables and state fixed effects are controlled for. Finally, the results show evidence of relational difficulty between Asians and both Blacks and Hispanics. The relevant effects are strongly significant across all three specifications.

Overall, these results show that people are more likely to engage in an activity which requires neighborhood social capital, the greater the incidence among their neighbors of persons of their own race. This result is consistent with the very simple social capital investment model outlined earlier, in which the role of what we term relational differences are emphasized. It is also consistent with the results from work such as that by Borjas (1995) who argues that the ethnic make-up of neighborhoods produce externalities which affect human capital accumulation. 
Interestingly, we find evidence for relational difficulties only for particular racial pairs. There is no evidence that Blacks and Hispanics have difficulty relating, nor that Whites and Asians do. Because the evidence from carpooling behavior suggests that every other type of neighborhood pairwise racial interaction is fraught with relational difficulty, it appears that races in the U.S. can be sorted into two groups (Blacks and Hispanics, and Whites and Asians) with social interaction relatively easy within a group and strained across groups.

\section{Robustness Test}

We have argued that because the instruments are exogenous with respect to the individual carpooling propensity, the TSLS regressions yield unbiased estimates of the effects of interest. But even if the instruments are exogenous as we have argued, there is no way to prove that the only way they affect carpooling is through their effect on adult neighborhood racial shares. While it is difficult to think of another mechanism by which they might, and while the effects are found for multiple specifications, we consider another estimation strategy to assess the robustness of the results shown above.

Our strategy is very simple. Suppose that people sort into neighborhoods, based on the racial distributions in those neighborhoods. Presumably, there are fixed costs associated with such sorting. But this means that for small departures from their desired neighborhood racial distribution, people should not sort. If someone wanted ideally to live in live in a 9\% Black PUMA, it seems very unlikely, given the sizes of PUMAs, that he would move if the arrival or departure of a few Black families changed the PUMA's Black make-up to 7 or $11 \%$. The presence of fixed costs of moving means that within neighborhoods with essentially the same overall racial distributions, sorting patterns should be essentially the same for people of a given race. If so, we can simply estimate equation (10) by O.L.S. on a sample drawn from these "essentially identical" neighborhoods. 
Earlier in the paper, we presented figures showing the fraction of each PUMA which was each race in 1990. These figures indicated that there are two types of neighborhoods in the U.S.: those in which the racial distribution was close to the national mean of the different races of the country and others, which could be thought of as "ethnic enclaves" in which the representation of ethnic minority neighborhood exceed the national share of the particular racial minority group. We find that if one focuses on the $63 \%$ of all PUMAs which are at least $80 \%$ White, the national mean across all PUMAs, these ethnic enclaves are dropped. What remains is a sample of PUMAs in which the representation of the various racial groups are all approximately equal to the national representation of the races. That these neighborhoods are essentially the same is evident in Appendix Table 2, which shows that the variances of all of the neighborhood racial share measures are very small in the restricted sample. The table shows also that the PUMAs dropped from the sample have more variance in the racial share terms than both the full and restricted sample.

Table 7 reports the results of an O.L.S. estimate of the relative difference model, estimated for individuals in the restricted sample of neighborhoods which are at least $80 \%$ White. ${ }^{20}$ The results control for individual level variables, PUMA level variables and state fixed effects. Standard errors are clustered by PUMA and corrected for heteroscedasticity. Overall, the results in Table 7 are strikingly similar to the TSLS results in Table 6. What we are interpreting as relational problems are found for Blacks and Whites; Blacks and Asians, Asians and Hispanics; while none are found for Whites and Asians or for Blacks and Hispanics. The only difference between the TSLS estimates and these restricted sample results are for White-Hispanic which are not significant in the latter case. That we find effects which are so similar in this alternative approach suggests that the results from the the TSLS technique estimate causal true effects of neighborhood distribution on carpooling and social capital production.

\footnotetext{
${ }^{20}$ Imposing the restriction that the PUMA be greater than $80 \%$ White causes us to drop $35 \%$ of the individual observations from the original sample. We retain $73 \%$ of Whites, $24 \%$ of the Blacks, $37 \%$ of the Asians, and $26 \%$ of the Hispanics.
} 


\section{Conclusion}

Most of the previous literature measures the effects of social capital, measured at the aggregate level, such as the state, region, or country. This paper assesses how social capital, measured at the individual level, is determined. It belongs to the small literature devoted to an "economic approach" to social capital (Glaeser, 2000).

We argue that an individual's propensity to invest in social capital, and consequently his accumulated stock of social capital, should be negatively affected by the difference between his own traits and the traits of those with whom he comes into contact, if these traits affect the ease, frequency or nature of social interaction. We examine whether race is a relational trait, focusing on the social relations between people in a neighborhood. Many previous authors have hinted that race is an important determinant of social interaction, but previous explicit tests of these ideas differ from the approach presented here for three main reasons.

First, we use an indicator of social capital never previously studied. Specifically, we study individual carpooling propensity as a measure of the social capital people have with others in their neighborhood. For a variety of reasons, we believe that carpooling is superior to previously used indicators of individual social capital. Second, our results do not merely focus on the effect of an aggregate measure of community diversity. Rather, we explicitly study the interaction between own and community characteristics for each distinct racial group. Third, and most importantly, our results rely on plausibly exogenous variation in neighborhood racial composition. Specifically, since people live in neighborhoods close to the state where they born, and since neighborhood racial composition is very spatially correlated, the racial composition of the state in which an individual was born in the year that he was born is a determinant of adult neighborhood racial composition which is plausibly unrelated to adult carpooling propensity. Using these state of birth / year of birth racial composition measures as instruments ensures that the results are purged of endogenity bias. 
Using a merged dataset from the 1990 1\% Census IPUMS, and the aggregate 1990 STF3 tables, we find that people are more likely to make social capital in their neighborhoods, as evidenced by their carpooling behavior, the greater the incidence among their neighbors of persons of the same race. Very interestingly, while this effect is true on average, we find that there are particular racial pairs for which no evidence of relational problems can be found.

Overall, our results indicate that the racial makeup of the neighborhoods in which people live affects the extent to which they form social connections with their neighbors, at least with respect to the particular activity we study. If this tendency extends to other activities, such as political participation, or to community organization, there are likely important public policy implications of this fact, given the growing racial diversity of the United States. To the extent that they show that people from different racial groups may have difficulty relating socially, our results are consistent with recent work which suggests that racial and ethnic diversity within communities is associated with lower spending on the poor (Alesina, Baquir and Easterly (1999), fewer public services, and lower support from public education, (Poterba (1998), and the differential expansion of high school education around the country (Goldin and Katz (1998)).

However, the results also indicate that the effects of racial diversity on outcomes is likely much more complicated than a simple "diversity is bad" argument. In particular, we find no evidence of relational problems for particular pairs of racial groups. Thus, increases in aggregate diversity will likely have very different effects on the people from different racial groups. This fact is missed in much of the previous literature which tends to relate an aggregate index of heterogeneity to individual outcomes, without allowing for separate individual effects by race.

Finally, the results in this paper and in other work leaves an important question unanswered: why does racial difference have the salience it appears to for social interaction? Unlike being able to speak the same language, there is no mechanical reason why people of different races should face 
relational difficulty. It is thus likely that race may be proxying for some other, more mechanical relational factor. Identifying that other factor is an important avenue for future work. 


\section{Bibliography}

Alesina, A., R. Baqir, and W. Easterly. 1999. "Public Goods and Ethnic Divisions." Quarterly Journal of Economics 114:1243-1284.

Alesina, A. and E. LaFerrara. 2000. "Participation in Heterogeneous Communities." Quarterly Journal of Economics 115:847-904.

Alesina, A., R. Baqir, and C. Hoxby, "Political Jurisdictions in Heterogeneous Communities," unpublished, 1999.

Arrow, Kenneth. 1972. "Gifts and Exchanges.” Philosophy and Public Affairs 1:343-363

Barsky, Robert, Bound, John, Charles, Kerwin and Lupton, Joseph. "Accounting for the Black-White Wealth Gap: A Non-Parametric Approach”, NBER Working Paper 8466.

Becker, Gary and Kevin M. Murphy. 2000. Social Economics. Cambridge: Harvard University Press.

Berg, J., J. Dickhaut, and K. McCabe. 1995. “Trust, Reciprocity, and Social History,' Games and Economic Behavior, X, 122-142.

Besley, Timothy. 1995. "Nonmarket Institutions for Credit and Risk Sharing in Low-Income Countries." The Journal of Economic Perspectives 9:115-127.

Borjas, George J. 1992. "Ethnic Capital and Intergenerational Mobility." Quarterly Journal of Economics 107:123-50.

1995. "Ethnicity, Neighborhoods, and Human Capital Externalities." American Economic Review 85:365-390.

Bound, J., D. Jaeger, and R. Baker. 1995. "Problems With Instrumental Variables Estimation When the Correlation Between the Instruments and The Endogenous Explanatory Variable is Weak." Journal of the American Statistical Association 90(430):443-450

Coleman, J. 1988. "Social Capital in the Creation of Human Capital." American Journal of Sociology 94:S95-S121.

1990. The Foundations of Social Theory. Cambridge: Harvard University Press.

Brock, W. and S. Durlauf. 1999. "Interaction Based Models." working paper, University of Wisconsin at Madison and forthcoming, Handbook of Econometrics 5, J. Heckman and E. Leamer eds., Amsterdam: North Holland.

Collier, P. 1998. "Social Capital and Poverty." Mimeo. Social Capital Initiative, The World Bank.

Costa, D. and M. Kahn. 2001. "Understanding The Decline in Social Capital, 1952-1998" NBER Working Paper \#8295. 
DiPasquale, D. and E. Glaeser. 1999. "Incentives and Social Capital: Are Homeowners Better Citizens?" Journal of Urban Economics 45:354-384.

Durlauf, Steven N. 1999. “The Case Against Social Capital.” Unpublished.

Ferguson, Erik. 1997. "The Rise and Fall of the American Carpool: 1970-1990." Transportation 24:349-376.

Fukuyama, F. 1995. Trust. New York: Free Press

Furstenberg, F. and M. Hughes. 1995. "Social Capital and Successful Development Among At-Risk Youth" Journal of Marriage and the Family 57:580-592.

Geolytics. 1998. Census CD+ Maps 2.1.

Glaeser, E., D. Laibson, and B. Sacerdote. 2000. “The Economic Approach to Social Capital.” NBER Working Paper \#7728.

Glaeser, E., D. Laibson, J. Scheinkman, and C. Soutter. 2000. "Measuring Trust.” Quarterly Journal of Economics 115:811-846.

Glaeser, E. and B. Sacerdote, 2000. "The Social Consequences of Housing." NBER Working Paper \#8034

Goldin, C., and L. Katz, "Human Capital and Social Capital: The Rise of Secondary Schooling in America, 1910-1940,' Journal of Interdisciplinary History, XXIX (1999), 683-723.

Gonzalez, Arturo. 1998. "Mexican Enclaves and the Price of Culture." Journal of Urban Economics 43:273-291.

Guiso, L., P. Sapienza, and L. Zingales. 2000. "The Role of Social Capital in Financial Development." NBER Working Paper \#7563.

Hall, Robert E. and C. Jones. 1999. "Why Do Some Countries Produce So Much More Output Per Worker Than Others?" Quarterly Journal of Economics 114:83-116

Helliwell, J. and R. Putnam. 1999. “Education and Social Capital.” NBER Working Paper \#7121.

Hoxby, Caroline and Daniel Paserman. 1998 "Overidentification Tests with Grouped Data”. NBER Technical Working Paper: \#223.

Huang, H., H. Yang, and M. Bell. 2000. "The Models and Economics of Carpools." Annals of Regional Science 34:55-68.

Jacobs, J., The Death and Life of Great American Cities (New York: Vintage, 1961).

Knack, S. and P. Keefer. 1997. "Does Social Capital Have an Economy Payoff? A Cross-Country Investigation," Quarterly Journal of Economics 112:1251-1288. 
La Porta, R., F. Lopez-de-Salanes, A Schleifer, and R. Vishny. 1997. "Trust in Large Organizations," American Economic Review Papers and Proceedings 87:333-338.

Laumann, E. and R. Sandefur. 1998. "A Paradigm for Social Capital." Rationality and Society. $10: 481-495$.

Loury, G., "A Dynamic Theory of Racial Income Differences," in Women, Minorities and Employment Discrimination, P. Wallace and A. LeMund, eds. (Lexington, MA: Lexington Books, 1977).

Massey, D. 1996. "The Age of Extremes: Concentrated Poverty and Affluence in the Twenty First Century." Demography 33:395-412.

Moulton, Brent R. 1990. "An Illustration of a Pitfall in Estimating The Effects of Aggregate Variables in Micro Units," Review of Economics and Statistics. Vol 72. 334-338.

Park, B. and M. Rothbart. 1982. "Perception of Out-Group Homogeneity and Levels of Social Categorization: Memory for the Subordinate Attributes of In-Group and Out-Group Members." Journal of Personality and Social Psychology 42:1051-1068.

Pettigrew, T. 1998. “Intergroup Contact Theory.” Annual Review of Psychology 49:65-85.

Portes, A. 1998. "Social Capital: Its Origins and Application in Modern Sociology." Annual Review of Sociology 1-14.

Portres, A. and P. Landolt. 1996. "The Downside of Social Capital." The American Prospect 26:1822.

Poterba, James. 1998. "Demographic Structure and the Political Economy of Public Education." NBER Working Paper, \#5677.

Putnam, R. 1993. Making Democracy Work: Civic Traditions in Modern Italy. Princeton: Princeton University Press.

Putnam, R. 1995. "Tuning in, tuning out: The strange disappearance of social capital in America" PS, Political Science \& Politics; Washington; Dec 1995.

Putnam, R. 2000. Bowling Alone: The Collapse and Revival of American Community. New York: Simon \& Schuster.

Staiger, D. and Stock, J.H. 1997. "Instrumental Variables Regression with Weak Instruments." Econometrica 65(3):557-586.

Tajfel, H. 1981. Human Groups and Social Categories Cambridge: Cambridge University Press.

Temple, Jonathan and Paul A. Johnson. 1998. "Social Capability and Economic Growth" Quarterly Journal of Economics 113:965-990.

Yitzhaki, Shiomo 1996. "On Using Linear Regressions in Welfare Economics," Journal of Business and Economic Statistics, 14(4), 478-486. 


\section{Data Appendix}

We included a number of controls that might be correlated with social capital, carpooling, and the neighborhood racial distribution. The controls can be divided into 3 categories: individual, geographic, and aggregate.

\section{Geographic Controls:}

Population Density (STF3): Measures the number of people per acre in an individual's PUMA.

Urban (IPUMS): Dummy indicating whether the individual lives in a census designated urbanized area. Since a PUMA can contain many neighborhoods that are part of urbanized areas and many that are not this gives us an approximation of the density of the individual's general town area. In many cases this town area is actually larger than a PUMA. If an individual lives in a metropolitan area, that whole area may be one Urbanized Area. Thus, one should think of the urban dummy as primarily serving as a contrast to rural status.

Small Lot (IPUMS): Dummy indicating whether an individual lives on a parcel of land less than an acre. This variable gives us an approximation of the density of the individual's immediate neighborhood.

City (IPUMS): Dummy indicating whether an individual lives in an incorporated city. Incorporated cities have population densities substantially higher than their surrounding urbanized areas. This is another approximation of "town" density.

\section{Individual Controls:}

All individual data comes from the 1990 IPUMS.

Number of Children in Household: Series of dummies for the number of the person's own children living in the household with him.

Household Size: Series of dummies for household size (in persons).

Married: Dummy for whether an individual is married.

Work in Same Puma: This variable is a dummy variable indicating whether an individual's PUMA matches the individual's PUMA of work.

Travel Time: Gives the total amount of time in minutes that it usually took the respondent to get from home to work last week, including any stops the worker usually made on the way to work.

Age: Series of age dummies.

Income: We measure Income as an individual's pre-tax wage and salary income. Income is specified in our regressions as a quadratic.

Education: Education is specified as a series of mutually exclusive dummies: high school or less, bachelor's or less, grad school or more. 
Homeowner: We include a dummy for homeownership in order to account for unobserved differences in wealth and community involvement.

Not Citizen: The 1990 Census asks citizenship status of all foreign-born respondents. We include a dummy for those foreign born respondents who indicate that they are not U.S. citizens.

Vehicles: Vehicles measures the number of vehicles in the individual's household. We break this variable into a series of dummies in the regressions.

Occupation \& Industry: We created a series of individual dymmies for occupation and industry based upon the 1990 Census Occupation \& Industry Schemes.

\section{Aggregate Controls:}

All aggregate data was constructed by matching block groups to PUMAs and then using block group level 1990 STF3 tables to estimate PUMA averages.

Education: We include variables for the percent of the PUMAs population over the age of 18 that has received a high school degree or less, bachelor's degree or less, and graduate degree or more.

Mean Travel Time: Mean (PUMA) Travel time to work represents the total number of minutes it usually took the person to get to work during the reference week. The elapsed time includes time spent waiting for public transportation, picking up passengers in carpools, and time spent in other activities related to getting to work.

Industry \& Occupation: We calculated the percent of each PUMAs working population that belonged to each industry and occupation type. These groups were made so as to match the individual groups.

Race and Language Group Dissimilarity: In order to calculate segregation levels differently for each group, we separated the entire population into members of that group and non-members. We then used a Stata plug-in ado file called "seg" to calculate the dissimilarity by PUMA between block groups in the composition of group members and non-group members. If there was no variation in the composition of group members and non-group members by block group than a PUMA was assigned a score of zero. If no group and non-group members lived in the same block group the PUMA was assigned a score of one, indicating complete segregation. See Duncan and Duncan (1955) for more on dissimilarity.

\footnotetext{
${ }^{21}$ For more on census occupation \& industry codes see http://www.ipums.umn.edu/usa/volii/99occup.html and http://www.ipums.umn.edu/usa/volii/99indus.html.
} 
Table 1: Summary Statistics

\begin{tabular}{|c|c|c|c|c|c|}
\hline Individual Characteristics & Mean & Std. Dev. & $\begin{array}{l}\text { Neighborhood (PUMA) Characteristics } \\
\end{array}$ & Mean & Std. Dev. \\
\hline Carpools (Riders >1) & 0.134 & 0.341 & Percent High School Grad or Less & 0.553 & 0.132 \\
\hline \multirow[t]{2}{*}{ Carpools (Riders >2) } & 0.031 & 0.174 & Percent More Than Bachelors & 0.061 & 0.040 \\
\hline & & & Mean Travel Time (Minutes) & 21.67 & 5.04 \\
\hline White & 0.836 & 0.371 & Population Density (Persons/Acre) & 1.333 & 3.323 \\
\hline Black & 0.090 & 0.286 & & & \\
\hline Asian-Pacific & 0.028 & 0.166 & Racial Composition Variables & & \\
\hline Hispanic & 0.039 & 0.193 & Percent White & 0.802 & 0.203 \\
\hline Other Race & 0.007 & 0.085 & Percent Black & 0.122 & 0.177 \\
\hline Age & 37.1 & 11.5 & Percent Asian & 0.029 & 0.062 \\
\hline Married & 0.642 & 0.479 & Percent Hispanic & 0.039 & 0.073 \\
\hline Size of Household & 3.298 & 1.585 & Percent Other & 0.009 & 0.027 \\
\hline In School & 0.103 & 0.304 & & & \\
\hline High School Grad or Less & 0.463 & 0.499 & & & \\
\hline More than Bachelors & 0.086 & 0.281 & & & \\
\hline Earnings & 28490 & 23759 & & & \\
\hline Not Citizen & 0.060 & 0.238 & & & \\
\hline Homeowner & 0.665 & 0.472 & & & \\
\hline Urban & 0.765 & 0.424 & & & \\
\hline Small Lot & 0.595 & 0.491 & & & \\
\hline City & 0.180 & 0.384 & & & \\
\hline Work In Same Puma & 0.629 & 0.483 & & & \\
\hline Travel Time (Minutes) & 24.53 & 18.32 & & & \\
\hline Number Of Vehicles In Household & 2.14 & 1.08 & & & \\
\hline Number of Individual Observation & 496280 & & Number of PUMAs & 1726 & \\
\hline
\end{tabular}

Sample includes working men age 18-64

Aggregate data compiled from STF3 block group tables matched with PUMAs 
Table 2: Mean Carpooling Among Different Racial and Language Groups, Under

Alternative Definitions of Carpooling

\begin{tabular}{lccc}
\hline \hline & Carpools (Riders >1) & Carpools (Riders >2) & Carpools (Riders >3) \\
\hline Full Sample & .134 & .031 & .013 \\
Race & & & .010 \\
White & .123 & .027 & .021 \\
Black & .176 & .046 & .017 \\
Asian & .153 & .039 & .041 \\
Hispanic & .242 & .086 & .020 \\
Other Race & .189 & .051 & .011 \\
Language & & & .036 \\
English Language & .126 & .027 & .018 \\
Spanish Language & .219 & .075 & .008 \\
French Language & .141 & .036 & .022 \\
Italian Language & .105 & .018 & .025 \\
German Language & .143 & .038 & .014 \\
Chinese Language & .147 & .046 & .036 \\
Other Language & .144 & & \\
\hline \hline
\end{tabular}


Table 3: First Stage Diagnostics

Excluded Instruments: 30 Terms Summarizing Racial Makeup of State of Birth in Year Born

\begin{tabular}{lcccc} 
& \multicolumn{3}{c}{ Endogenous Regressor: Fraction of PUMA in 1990 Which Is: } \\
\cline { 2 - 5 } Statistic & White & Black & Asian & Hispanic \\
\hline Partial R2 & 0.0040 & 0.0045 & 0.0009 & 0.0043 \\
F (clustered by state and decade of birth) & 13.78 & 11.01 & 11.65 & 9.89 \\
$\quad$ p value & 0.0000 & 0.0000 & 0.0000 & 0.0000 \\
& & & & \\
Number of Observations & 436,262 & 436,262 & 436,262 & 436,262 \\
Number of State-Decade Clusters & 247 & 247 & 247 & 247 \\
\hline \hline See Text for Further Explanation & & &
\end{tabular}

See Text for Further Explanation 
Table 4: Linear Probability Estimate of Carpooling Determinants Among Working Men Age 1 64 From Merged IPUMS-STF3 Data

\begin{tabular}{|c|c|c|}
\hline & $\begin{array}{c}(1) \\
\text { Carpools: Riders >1 } \\
\end{array}$ & $\begin{array}{c}(2) \\
\text { Carpools: Riders >2 }\end{array}$ \\
\hline \multirow[t]{2}{*}{ Age $18-22$} & 0.0471 & 0.0049 \\
\hline & $(0.0029)$ & $(0.0015)$ \\
\hline \multirow[t]{2}{*}{ Age 23-30 } & 0.0291 & 0.0034 \\
\hline & $(0.0020)$ & $(0.0010)$ \\
\hline \multirow[t]{2}{*}{ Age $31-45$} & 0.0135 & -0.0013 \\
\hline & $(0.0019)$ & $(0.0009)$ \\
\hline \multirow[t]{2}{*}{ Age $46-55$} & 0.0163 & 0.0020 \\
\hline & $(0.0019)$ & $(0.0009)$ \\
\hline \multirow[t]{2}{*}{ Married } & 0.0148 & 0.0016 \\
\hline & $(0.0016)$ & $(0.0008)$ \\
\hline \multirow[t]{2}{*}{ In School } & -0.0254 & -0.0073 \\
\hline & $(0.0017)$ & $(0.0009)$ \\
\hline \multirow[t]{2}{*}{ Bachelor's Degree } & -0.0257 & -0.0071 \\
\hline & $(0.0012)$ & $(0.0006)$ \\
\hline \multirow[t]{2}{*}{ Grad School + } & -0.0180 & -0.0038 \\
\hline & $(0.0020)$ & $(0.0010)$ \\
\hline \multirow[t]{2}{*}{ Log Earnings } & 0.0365 & -0.0003 \\
\hline & $(0.0059)$ & $(0.0033)$ \\
\hline \multirow[t]{2}{*}{ Log Earnings Squared } & -0.0030 & -0.0002 \\
\hline & $(0.0003)$ & $(0.0002)$ \\
\hline \multirow[t]{2}{*}{ Homeowner } & -0.0183 & -0.0056 \\
\hline & $(0.0014)$ & $(0.0008)$ \\
\hline \multirow[t]{2}{*}{ Urban } & 0.0014 & 0.0046 \\
\hline & $(0.0017)$ & (0.0009) \\
\hline \multirow[t]{2}{*}{ Small Lot } & 0.0007 & 0.0002 \\
\hline & $(0.0013)$ & $(0.0007)$ \\
\hline \multirow[t]{2}{*}{ City } & -0.0032 & -0.0007 \\
\hline & $(0.0024)$ & $(0.0012)$ \\
\hline \multirow[t]{2}{*}{ Work In Same Puma } & -0.0164 & -0.0116 \\
\hline & $(0.0015)$ & $(0.0009)$ \\
\hline \multirow[t]{2}{*}{ Log Travel Time } & 0.0405 & 0.0188 \\
\hline & (0.0009) & $(0.0006)$ \\
\hline \multirow[t]{2}{*}{$1 \mathrm{Car}$} & 0.0302 & -0.0133 \\
\hline & $(0.0038)$ & $(0.0024)$ \\
\hline \multirow[t]{2}{*}{2 Cars } & -0.0470 & -0.0307 \\
\hline & $(0.0042)$ & $(0.0025)$ \\
\hline \multirow[t]{2}{*}{3 Cars } & -0.0591 & -0.0337 \\
\hline & $(0.0043)$ & $(0.0026)$ \\
\hline \multirow[t]{2}{*}{ 4+ Cars } & -0.0722 & -0.0409 \\
\hline & $(0.0046)$ & $(0.0027)$ \\
\hline Log Population Density & -0.0027 & -0.0010 \\
\hline & $(0.0009)$ & $(0.0005)$ \\
\hline Percent Bachelor's Degree & 0.0451 & 0.0057 \\
\hline & $(0.0218)$ & $(0.0117)$ \\
\hline Percent Grad School + & 0.2706 & 0.0615 \\
\hline & $(0.0764)$ & $(0.0427)$ \\
\hline Log Mean Travel Time & -0.0228 & -0.0017 \\
\hline & $(0.0063)$ & $(0.0033)$ \\
\hline Child Dummies & Yes & Yes \\
\hline Household Size Dummies & Yes & Yes \\
\hline Occupational Controls & Yes & Yes \\
\hline Industry Controls & Yes & Yes \\
\hline Observations & 496280 & 496280 \\
\hline PUMAs & 1726 & 1726 \\
\hline R-squared & 0.0609 & 0.0386 \\
\hline
\end{tabular}

Data drawn from merged IPUMS Census Sample. Controls not shown included in Appendix Table 2.

All regressions include controls for state fixed effects.

Standard errors adjusted for clustering by PUMA 
Table 5: Linear Probability Estimates of Difference-in-Difference of Effect of PUMA Racial Distribution on Probability of Carpooling

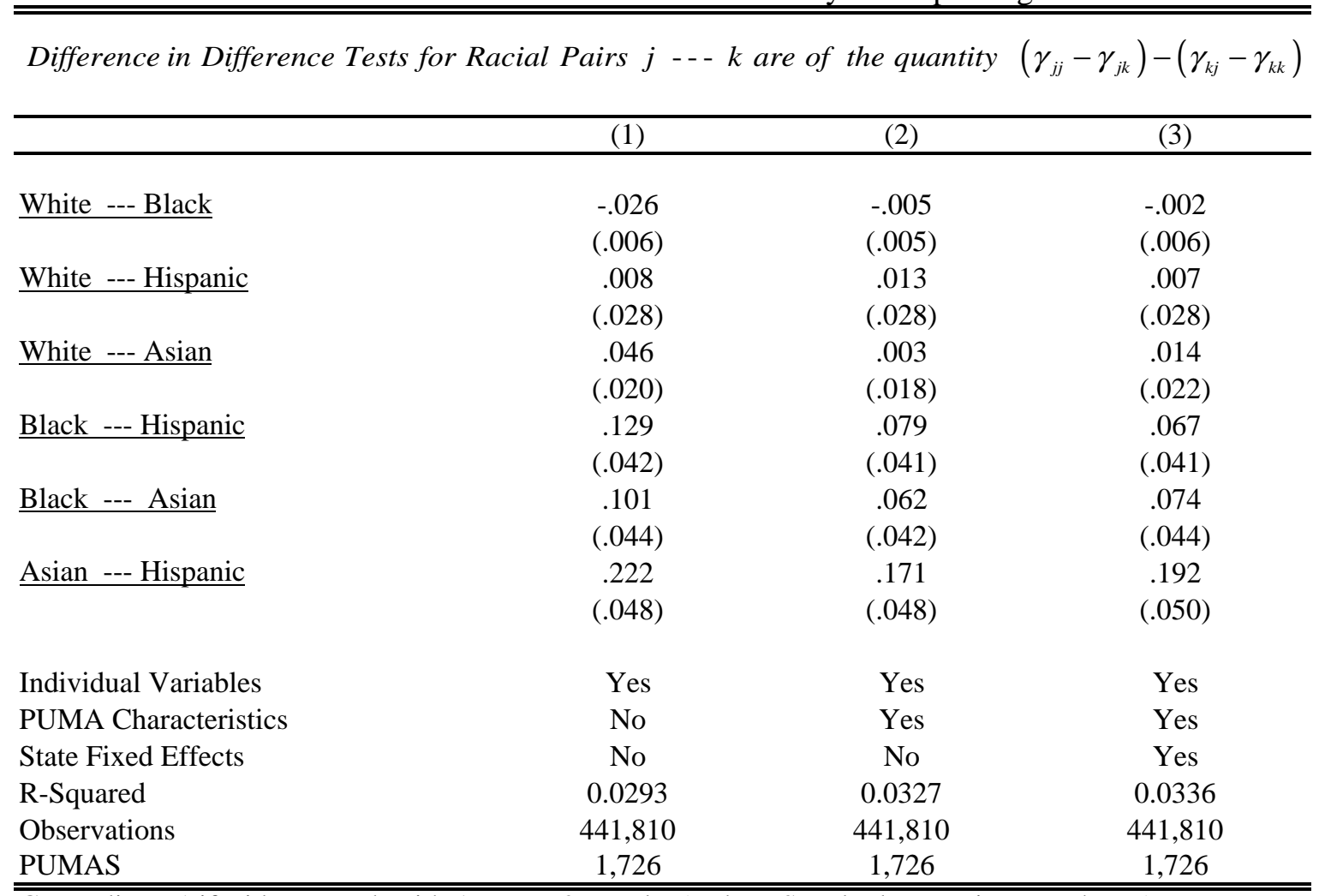

Carpooling =1 if Ride to Work with At Least 2 People. (Robust Standard Errors in Parentheses) 
Table 6: TSLS Linear Probability Estimates of Difference-in-Difference of Effect of PUMA Racial Distribution on Probability of Carpooling

\begin{tabular}{|c|c|c|c|}
\hline & (1) & (2) & (3) \\
\hline \multirow[t]{2}{*}{ White --- Black } & .034 & .363 & .317 \\
\hline & $(.108)$ & $(.136)$ & $(.114)$ \\
\hline \multirow{2}{*}{ White --- Hispanic } & .738 & .618 & .438 \\
\hline & $(.196)$ & $(.244)$ & $(.263)$ \\
\hline \multirow[t]{2}{*}{ White --- Asian } & .005 & -.066 & -.116 \\
\hline & $(.116)$ & $(.099)$ & $(.094)$ \\
\hline \multirow[t]{2}{*}{ Black --- Hispanic } & .899 & .226 & .142 \\
\hline & $(.703)$ & $(.637)$ & $(.387)$ \\
\hline \multirow[t]{2}{*}{ Black --- Asian } & .526 & 1.024 & .986 \\
\hline & $(1.130)$ & (1.033) & $(.589)$ \\
\hline \multirow[t]{2}{*}{ Asian --- Hispanic } & 1.095 & 1.178 & 1.607 \\
\hline & $(.487)$ & $(.518)$ & $(.681)$ \\
\hline Individual Variables & Yes & Yes & Yes \\
\hline PUMA Characteristics & No & Yes & Yes \\
\hline State Fixed Effects & No & No & Yes \\
\hline R-Squared & N/A & N/A & N/A \\
\hline Observations & 436,262 & 436,262 & 436,262 \\
\hline PUMAS & 1,726 & 1,726 & 1,726 \\
\hline State-Decade Clusters & 247 & 247 & 247 \\
\hline
\end{tabular}

Carpooling $=1$ if Ride to Work with At Least 2 People.

Standard errors clustered by state and decade of birth 
Table 7: OLS Difference-in-Difference of Effect of

PUMA Racial Distribution on Probability of Carpooling Estimated on PUMAs at Least 80\% White

Difference in Difference Tests for Racial Pairs $j---k$ are of the quantity $\left(\gamma_{j j}-\gamma_{j k}\right)-\left(\gamma_{k j}-\gamma_{k k}\right)$

\begin{tabular}{|c|c|}
\hline White --- Black & .098 \\
\hline & $(.047)$ \\
\hline White --- Hispanic & .122 \\
\hline & $(.144)$ \\
\hline White --- Asian & -.011 \\
\hline & $(.083)$ \\
\hline Black --- Hispanic & -.058 \\
\hline & $(.232)$ \\
\hline Black --- Asian & .275 \\
\hline & $(.154)$ \\
\hline Asian --- Hispanic & .736 \\
\hline & $(.265)$ \\
\hline Individual Variables & Yes \\
\hline PUMA Characteristics & No \\
\hline State Fixed Effects & No \\
\hline R-Squared & 0.0357 \\
\hline Observations & 324,145 \\
\hline PUMAS & 1,096 \\
\hline
\end{tabular}

Carpooling =1 if Ride to Work with At Least 2 People. (Robust Standard Errors in Parentheses) 
Appendix Table 1: Extra Controls for Base Regressions

\begin{tabular}{|c|c|c|c|}
\hline & $\begin{array}{c}\text { (1) } \\
\text { Carpools: Riders >1 }\end{array}$ & $\begin{array}{c}(2) \\
\text { Carpools: Riders >2 }\end{array}$ & $\begin{array}{c}\text { (3) } \\
\text { Carpools: Riders }>3 \\
\end{array}$ \\
\hline \multirow[t]{2}{*}{1 Child } & -0.0101 & -0.0040 & -0.0042 \\
\hline & $(0.0022)$ & $(0.0011)$ & $(0.0008)$ \\
\hline \multirow[t]{2}{*}{2 Children } & -0.0310 & -0.0077 & -0.0047 \\
\hline & $(0.0027)$ & $(0.0015)$ & $(0.0012)$ \\
\hline \multirow[t]{2}{*}{3 Children } & -0.0455 & -0.0147 & -0.0060 \\
\hline & $(0.0035)$ & $(0.0021)$ & $(0.0016)$ \\
\hline \multirow[t]{2}{*}{4 Children } & -0.0701 & -0.0284 & -0.0151 \\
\hline & $(0.0050)$ & $(0.0033)$ & $(0.0025)$ \\
\hline \multirow[t]{2}{*}{1 Person Household } & -0.1818 & -0.0610 & -0.0293 \\
\hline & $(0.0041)$ & $(0.0027)$ & $(0.0020)$ \\
\hline \multirow[t]{2}{*}{2 Person Household } & -0.0890 & -0.0506 & -0.0250 \\
\hline & $(0.0036)$ & $(0.0025)$ & $(0.0020)$ \\
\hline \multirow[t]{2}{*}{3 Person Household } & -0.0776 & -0.0371 & -0.0203 \\
\hline & $(0.0036)$ & $(0.0025)$ & $(0.0018)$ \\
\hline \multirow[t]{2}{*}{4 Person Household } & -0.0605 & -0.0294 & -0.0149 \\
\hline & $(0.0035)$ & $(0.0023)$ & $(0.0017)$ \\
\hline \multirow[t]{2}{*}{5 Person Household } & -0.0393 & -0.0193 & -0.0113 \\
\hline & $(0.0037)$ & $(0.0025)$ & $(0.0018)$ \\
\hline \multirow[t]{2}{*}{ Not Citizen } & 0.0387 & 0.0281 & 0.0149 \\
\hline & $(0.0032)$ & $(0.0021)$ & $(0.0015)$ \\
\hline \multirow[t]{2}{*}{ Managerial or Professional Occupation } & -0.0736 & -0.0464 & -0.0295 \\
\hline & $(0.0062)$ & $(0.0045)$ & $(0.0036)$ \\
\hline \multirow[t]{2}{*}{ Technical, Sales, or Administrative Support Occupation } & -0.0800 & -0.0501 & -0.0314 \\
\hline & $(0.0062)$ & $(0.0045)$ & $(0.0036)$ \\
\hline \multirow[t]{2}{*}{ Service Occupation } & -0.0845 & -0.0545 & -0.0338 \\
\hline & $(0.0063)$ & $(0.0046)$ & $(0.0037)$ \\
\hline \multirow[t]{2}{*}{ Farming, Forestry, or Fishing Occupatoin } & 0.0000 & 0.0000 & 0.0000 \\
\hline & $(0.0000)$ & $(0.0000)$ & $(0.0000)$ \\
\hline \multirow[t]{2}{*}{ Precision, Production, Craft, or Repair Occupation } & -0.0517 & -0.0428 & -0.0289 \\
\hline & $(0.0063)$ & $(0.0046)$ & $(0.0037)$ \\
\hline \multirow[t]{2}{*}{ Operator, Fabricator, or Repair Occupation } & -0.0578 & -0.0442 & -0.0295 \\
\hline & $(0.0063)$ & $(0.0046)$ & $(0.0037)$ \\
\hline \multirow[t]{2}{*}{ Military Occupation } & -0.0877 & -0.0449 & -0.0300 \\
\hline & $(0.0098)$ & $(0.0060)$ & $(0.0044)$ \\
\hline \multirow[t]{2}{*}{ Agriculture, Forestry, or Fishing Industry } & 0.0000 & 0.0000 & 0.0000 \\
\hline & $(0.0000)$ & $(0.0000)$ & $(0.0000)$ \\
\hline \multirow[t]{2}{*}{ Mining Industry } & 0.0421 & 0.0271 & 0.0167 \\
\hline & $(0.0095)$ & $(0.0072)$ & $(0.0053)$ \\
\hline Construction Industry & 0.0499 & 0.0005 & -0.0060 \\
\hline & $(0.0067)$ & $(0.0048)$ & $(0.0037)$ \\
\hline Nondurable Manufacturing Industry & -0.0117 & -0.0241 & -0.0150 \\
\hline & $(0.0066)$ & $(0.0047)$ & $(0.0036)$ \\
\hline Durable Manufacturing Industry & 0.0090 & -0.0143 & -0.0081 \\
\hline & $(0.0065)$ & $(0.0047)$ & $(0.0036)$ \\
\hline Transportation, Communications, or Other Public Utility Industry & -0.0354 & -0.0285 & -0.0148 \\
\hline & $(0.0064)$ & $(0.0046)$ & $(0.0035)$ \\
\hline Wholesale Trade Industry & -0.0316 & -0.0290 & -0.0166 \\
\hline & $(0.0065)$ & $(0.0047)$ & $(0.0036)$ \\
\hline Retail Trade Industry & -0.0476 & -0.0352 & -0.0177 \\
\hline & $(0.0064)$ & $(0.0046)$ & $(0.0036)$ \\
\hline Finance, Insurance, or Real Estate Industry & -0.0215 & -0.0273 & -0.0150 \\
\hline & $(0.0065)$ & $(0.0046)$ & $(0.0036)$ \\
\hline Business or Repair Services Industry & -0.0298 & -0.0311 & -0.0165 \\
\hline & $(0.0066)$ & $(0.0047)$ & $(0.0036)$ \\
\hline Personal Services Industry & -0.0321 & -0.0332 & -0.0191 \\
\hline & $(0.0073)$ & $(0.0049)$ & $(0.0037)$ \\
\hline
\end{tabular}


Appendix Table 1: Extra Controls for Base Regressions (continued)

\begin{tabular}{|c|c|c|c|}
\hline & $\begin{array}{c}1) \\
\text { Riders }>1 \\
\end{array}$ & $\begin{array}{c}(2) \\
\text { Riders }>2 \\
\end{array}$ & $\begin{array}{c}3) \\
\text { Riders }>3 \\
\end{array}$ \\
\hline Entertainment or Recreation Services Industry & $\begin{array}{c}-0.0253 \\
(0.0074)\end{array}$ & $\begin{array}{c}-0.0309 \\
(0.0050)\end{array}$ & $\begin{array}{c}-0.0165 \\
(0.0038)\end{array}$ \\
\hline Professional or Related Services Industry & $\begin{array}{c}0.0004 \\
(0.0065)\end{array}$ & $\begin{array}{l}-0.0202 \\
(0.0046)\end{array}$ & $\begin{array}{c}-0.0115 \\
(0.0036)\end{array}$ \\
\hline Public Administration Industry & $\begin{array}{c}0.0074 \\
(0.0067)\end{array}$ & $\begin{array}{l}-0.0125 \\
(0.0047)\end{array}$ & $\begin{array}{l}-0.0066 \\
(0.0036)\end{array}$ \\
\hline Military Industry & $\begin{array}{l}-0.0227 \\
(0.0080)\end{array}$ & $\begin{array}{c}-0.0264 \\
(0.0056)\end{array}$ & $\begin{array}{l}-0.0129 \\
(0.0041)\end{array}$ \\
\hline Percent Agriculture, Forestry, and Fishing Industry & $\begin{array}{c}0.2126 \\
(0.0537)\end{array}$ & $\begin{array}{c}0.2329 \\
(0.0326)\end{array}$ & $\begin{array}{c}0.1749 \\
(0.0237)\end{array}$ \\
\hline Percent Mining Industry & $\begin{array}{c}1.0268 \\
(0.2886)\end{array}$ & $\begin{array}{c}0.7824 \\
(0.1839)\end{array}$ & $\begin{array}{c}0.3917 \\
(0.1573)\end{array}$ \\
\hline Percent Construction Industry & $\begin{array}{c}1.0712 \\
(0.2913)\end{array}$ & $\begin{array}{c}0.7420 \\
(0.1904)\end{array}$ & $\begin{array}{c}0.3596 \\
(0.1626)\end{array}$ \\
\hline Percent Nondurables Manufacturing Industry & $\begin{array}{c}0.8279 \\
(0.2853)\end{array}$ & $\begin{array}{c}0.6765 \\
(0.1807)\end{array}$ & $\begin{array}{c}0.3510 \\
(0.1540)\end{array}$ \\
\hline Percent Durables Manufacturing Industry & $\begin{array}{c}0.8471 \\
(0.2852)\end{array}$ & $\begin{array}{c}0.6328 \\
(0.1795)\end{array}$ & $\begin{array}{c}0.3167 \\
(0.1536)\end{array}$ \\
\hline Percent Transportation Industry & $\begin{array}{c}0.7230 \\
(0.2935)\end{array}$ & $\begin{array}{c}0.6026 \\
(0.1860)\end{array}$ & $\begin{array}{c}0.2812 \\
(0.1586)\end{array}$ \\
\hline Percent Communications Industry & $\begin{array}{c}1.3499 \\
(0.3027)\end{array}$ & $\begin{array}{c}0.7666 \\
(0.1874)\end{array}$ & $\begin{array}{c}0.3477 \\
(0.1590)\end{array}$ \\
\hline Percent Wholesale Trade Industry & $\begin{array}{c}0.8520 \\
(0.3041)\end{array}$ & $\begin{array}{c}0.5820 \\
(0.1967)\end{array}$ & $\begin{array}{c}0.2663 \\
(0.1677)\end{array}$ \\
\hline Percent Retail Trade Industry & $\begin{array}{c}0.9231 \\
(0.2868)\end{array}$ & $\begin{array}{c}0.7041 \\
(0.1813)\end{array}$ & $\begin{array}{c}0.3439 \\
(0.1550)\end{array}$ \\
\hline Percent Finance, Insurance, and Real Estate Industry & $\begin{array}{c}0.9045 \\
(0.2933)\end{array}$ & $\begin{array}{c}0.6936 \\
(0.1889)\end{array}$ & $\begin{array}{c}0.3236 \\
(0.1598)\end{array}$ \\
\hline Percent Business \& Repair Services Industry & $\begin{array}{c}0.8545 \\
(0.3028)\end{array}$ & $\begin{array}{c}0.7080 \\
(0.1860)\end{array}$ & $\begin{array}{c}0.3379 \\
(0.1541)\end{array}$ \\
\hline Percent Personal Services Industry & $\begin{array}{c}0.9385 \\
(0.2988)\end{array}$ & $\begin{array}{c}0.5658 \\
(0.1841)\end{array}$ & $\begin{array}{c}0.2802 \\
(0.1572)\end{array}$ \\
\hline Percent Entertainment \& Recreation Services Industry & $\begin{array}{c}1.0287 \\
(0.2970)\end{array}$ & $\begin{array}{c}0.6763 \\
(0.1844)\end{array}$ & $\begin{array}{c}0.3174 \\
(0.1558)\end{array}$ \\
\hline Percent Health Services Industry & $\begin{array}{c}0.9982 \\
(0.2869)\end{array}$ & $\begin{array}{c}0.7013 \\
(0.1784)\end{array}$ & $\begin{array}{c}0.3288 \\
(0.1513)\end{array}$ \\
\hline Percent Educational Services Industry & $\begin{array}{c}0.9274 \\
(0.2894)\end{array}$ & $\begin{array}{c}0.6729 \\
(0.1814)\end{array}$ & $\begin{array}{c}0.3204 \\
(0.1548)\end{array}$ \\
\hline Percent Other Professional \& Related Specialties Industry & $\begin{array}{c}0.6931 \\
(0.3020)\end{array}$ & $\begin{array}{c}0.5778 \\
(0.1852)\end{array}$ & $\begin{array}{c}0.2961 \\
(0.1583)\end{array}$ \\
\hline Percent Public Administration Industry & $\begin{array}{c}1.1921 \\
(0.2866)\end{array}$ & $\begin{array}{c}0.7892 \\
(0.1826)\end{array}$ & $\begin{array}{c}0.3889 \\
(0.1559)\end{array}$ \\
\hline Percent Executive, Administrative, and Managerial Occupation & $\begin{array}{l}-0.9652 \\
(0.2984)\end{array}$ & $\begin{array}{c}-0.6502 \\
(0.1909)\end{array}$ & $\begin{array}{l}-0.3261 \\
(0.1587)\end{array}$ \\
\hline Percent Professional Specialty Occupation & $\begin{array}{l}-1.0408 \\
(0.2934)\end{array}$ & $\begin{array}{l}-0.6765 \\
(0.1800)\end{array}$ & $\begin{array}{l}-0.3175 \\
(0.1540)\end{array}$ \\
\hline Percent Technicians \& Related Support Occupation & $\begin{array}{c}-0.7169 \\
(0.3094)\end{array}$ & $\begin{array}{l}-0.6065 \\
(0.1869)\end{array}$ & $\begin{array}{l}-0.2750 \\
(0.1576)\end{array}$ \\
\hline Percent Sales Occupation & $\begin{array}{c}-0.8809 \\
(0.2929)\end{array}$ & $\begin{array}{c}-0.6873 \\
(0.1871)\end{array}$ & $\begin{array}{c}-0.2966 \\
(0.1595)\end{array}$ \\
\hline Percent Administrative Support Occupation & $\begin{array}{l}-1.0054 \\
(0.2900)\end{array}$ & $\begin{array}{c}-0.7489 \\
(0.1854)\end{array}$ & $\begin{array}{c}-0.3448 \\
(0.1580)\end{array}$ \\
\hline Percent Private Services Occupation & $\begin{array}{l}-1.2490 \\
(0.4052)\end{array}$ & $\begin{array}{c}-0.8297 \\
(0.2350)\end{array}$ & $\begin{array}{l}-0.3605 \\
(0.1714)\end{array}$ \\
\hline Percent Protective Services Occupation & $\begin{array}{l}-0.4779 \\
(0.3079)\end{array}$ & $\begin{array}{c}-0.5220 \\
(0.1878)\end{array}$ & $\begin{array}{c}-0.2786 \\
(0.1538)\end{array}$ \\
\hline
\end{tabular}


Appendix Table 1: Extra Controls for Base Regressions (continued)

\begin{tabular}{|c|c|c|c|}
\hline & (1) & (2) & (3) \\
\hline & Riders $>1$ & Riders $>2$ & Riders $>3$ \\
\hline \multirow[t]{2}{*}{ Percent Other Services Occupation } & -1.0448 & -0.6759 & -0.3254 \\
\hline & $(0.2941)$ & $(0.1806)$ & $(0.1522)$ \\
\hline \multirow[t]{2}{*}{ Percent Farming, Forestry, and Fishing Occupation } & 0.0000 & 0.0000 & 0.0000 \\
\hline & $(0.0000)$ & $(0.0000)$ & $(0.0000)$ \\
\hline \multirow[t]{2}{*}{ Percent Precision Production, Craft, \& Repair Occupation } & -0.8071 & -0.6736 & -0.3370 \\
\hline & $(0.2837)$ & $(0.1799)$ & $(0.1524)$ \\
\hline \multirow[t]{2}{*}{ Percent Machine Operators, Assemblers, \& Inspectors Occupation } & -0.6588 & -0.6119 & -0.3203 \\
\hline & $(0.2887)$ & $(0.1800)$ & $(0.1525)$ \\
\hline \multirow[t]{2}{*}{ Percent Transportation \& Material Moving Occupation } & -1.0788 & -0.8041 & -0.3874 \\
\hline & $(0.3235)$ & $(0.2023)$ & $(0.1704)$ \\
\hline \multirow[t]{2}{*}{ Percent Handlers, Equipment Cleaners, Helpers \& Laborers Occupation } & -0.4471 & -0.3264 & -0.1255 \\
\hline & $(0.3222)$ & $(0.2045)$ & $(0.1696)$ \\
\hline Observations & 496280 & 496280 & 496280 \\
\hline PUMAs & 1726 & 1726 & 1726 \\
\hline R-squared & 0.0609 & 0.0386 & 0.0234 \\
\hline
\end{tabular}

All regressions include controls for state fixed effects.

Standard errors adjusted for clustering by PUMA 
Appendix Table 2: Variance of (Percent Puma Given Type), by Puma in Full Sample, Restricted Sample, and Dropped Sample

\begin{tabular}{|c|c|c|c|c|c|}
\hline \multirow[b]{2}{*}{$\begin{array}{l}\text { Share of PUMA: } \\
\text { Race }\end{array}$} & \multirow{2}{*}{$\begin{array}{l}\text { Full Sample } \\
\text { Variance }\end{array}$} & \multicolumn{2}{|c|}{ Percent PUMA White > 80\% } & \multicolumn{2}{|c|}{ Percent PUMA White $<80 \%$} \\
\hline & & Variance & Variance Ratio & Variance & Variance Ratio \\
\hline White & 0.04111 & 0.00284 & 0.07 & 0.19600 & 4.77 \\
\hline Black & 0.03119 & 0.00175 & 0.06 & 0.05006 & 1.60 \\
\hline Asian & 0.00383 & 0.00039 & 0.10 & 0.00905 & 2.36 \\
\hline Hispanic & 0.00530 & 0.00057 & 0.11 & 0.01080 & 2.04 \\
\hline Other & 0.00075 & 0.00020 & 0.26 & 0.00171 & 2.27 \\
\hline
\end{tabular}




\section{PUMA of Residence Among Men Age 18-64 Born in lowa}

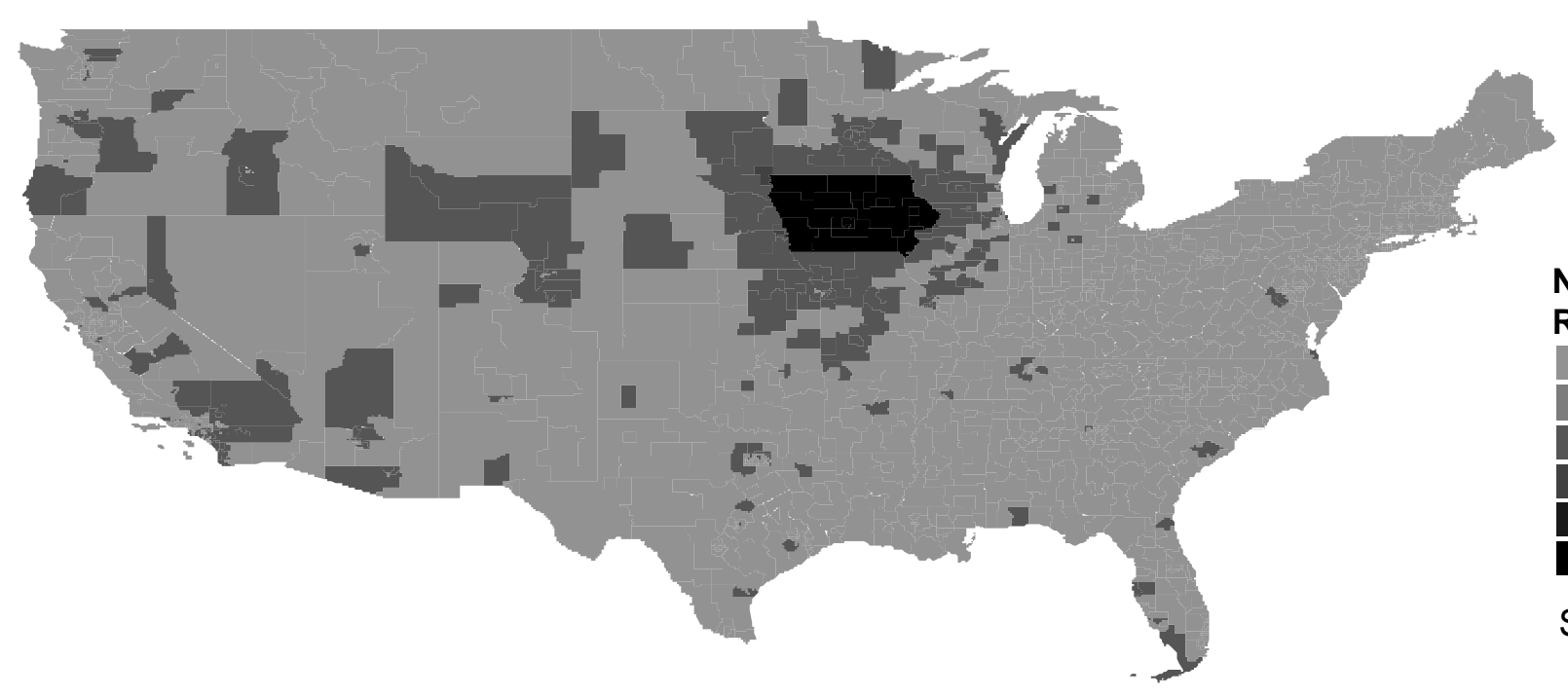

Number of Native lowans in PUMA Relative to Mean Across All PUMAS

0 - 1 Std. Dev. Below Mean National Mean

0 - 1 Std. Dev. Above Mean

1 - 2 Std. Dev. Above Mean

2 - 3 Std. Dev. Above Mean

> 3 Std. Dev. Above Mean

Source: 1990 IPUMS 


\section{PUMA of Residence Among Men Age 18-64 Born in Massachusetts}

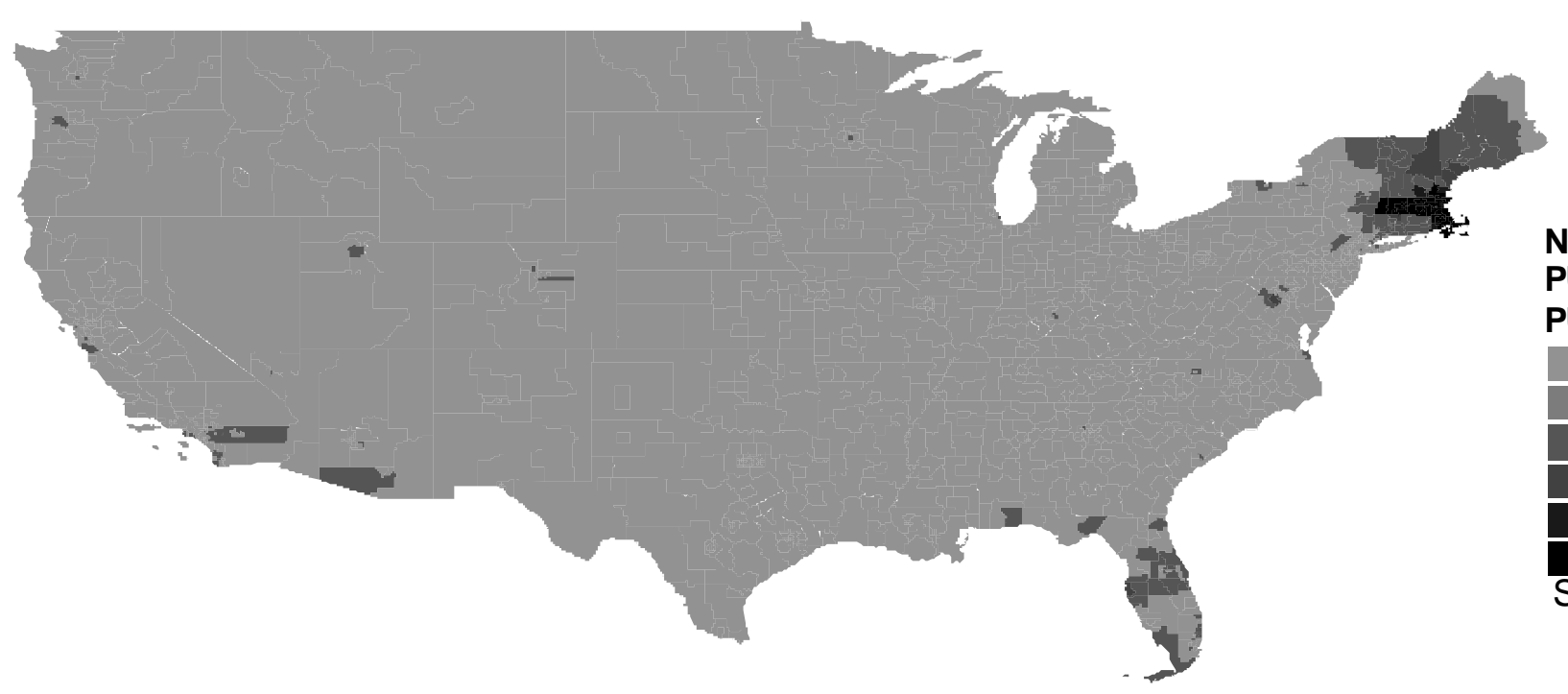

Number Born in Massachusetts in PUMA Relative to Mean Across Al PUMAS

0 - 1 Std. Dev. Below Mean National Mean

0 - 1 Std. Dev. Above Mean

1 - 2 Std. Dev. Above Mean

2 - 3 Std. Dev. Above Mean $>3$ Std. Dev. Above Mean Source: 1990 IPUMS 


\section{PUMA of Residence Among Men Age 18-64 Born in California}

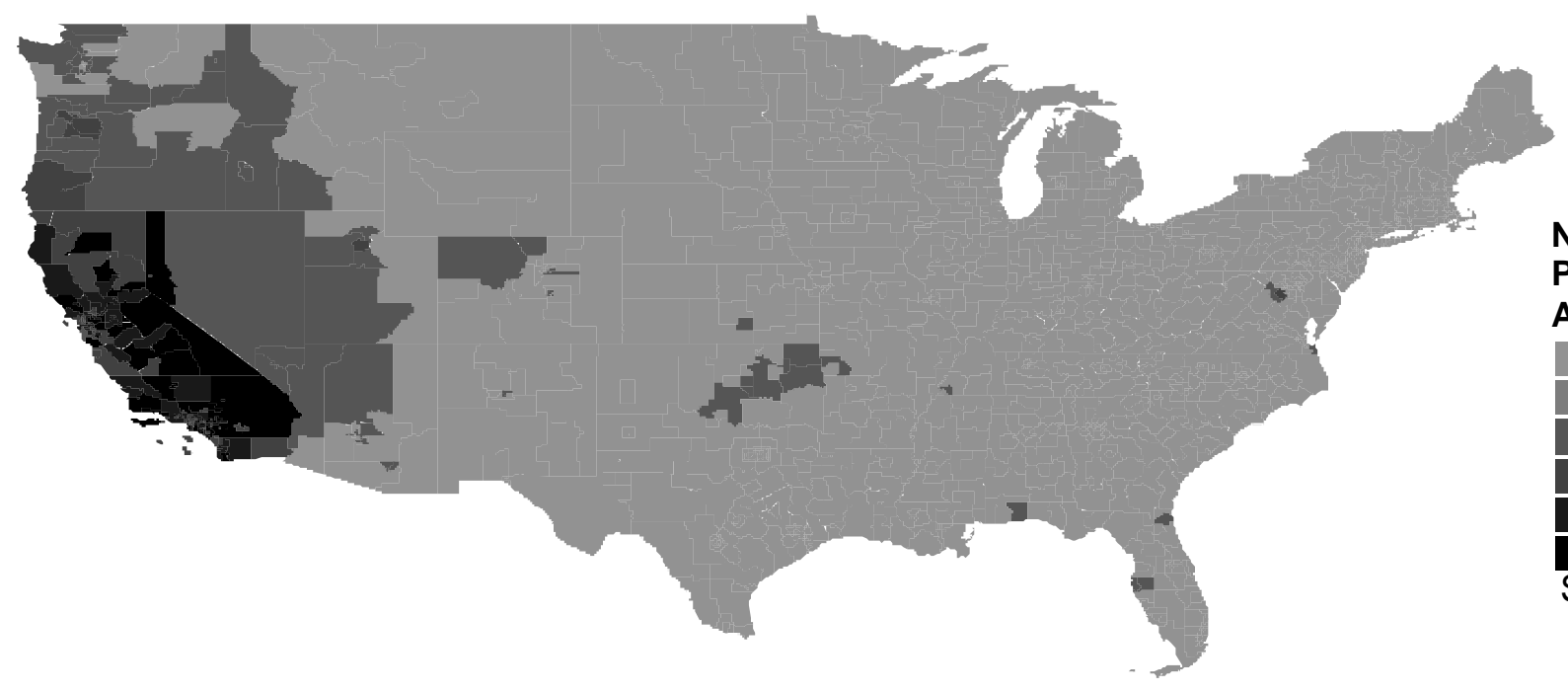

Number of Native Californians in PUMA Relative to Mean Across All PUMAS

0 - 1 Std. Dev. Below Mean

National Mean

0 - 1 Std. Dev. Above Mean

1 - 2 Std. Dev. Above Mean

2 - 3 Std. Dev. Above Mean $>3$ Std. Dev. Above Mean Source: 1990 IPUMS 


\section{PUMA of Residence Among Men Age 18-64 Born in Alabama}

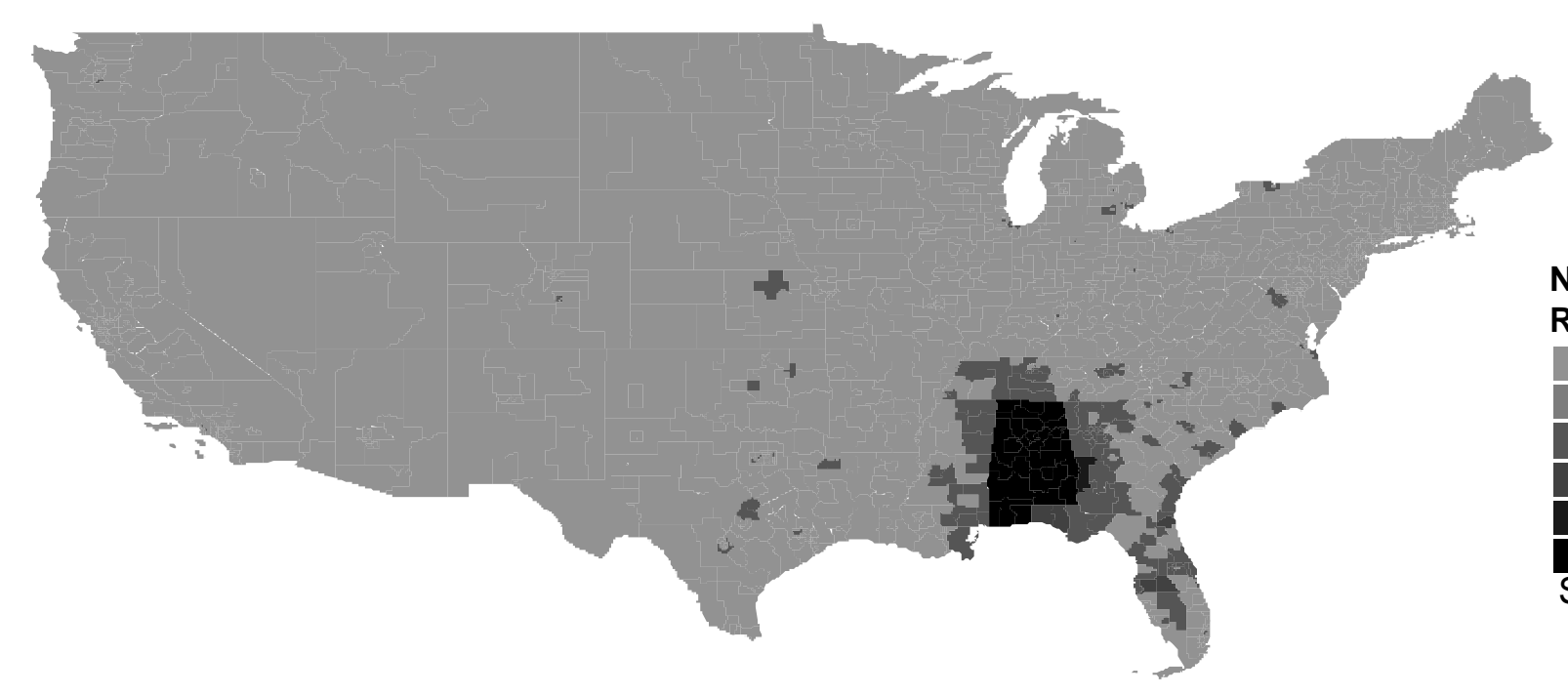

Number Born in Alabama in PUMA Relative to Mean Across All PUMAS 0 - 1 Std. Dev. Below Mean National Mean

0 - 1 Std. Dev. Above Mean

1 - 2 Std. Dev. Above Mean

2 - 3 Std. Dev. Above Mean $>3$ Std. Dev. Above Mean Source: 1990 IPUMS 


\section{Percent PUMA White}

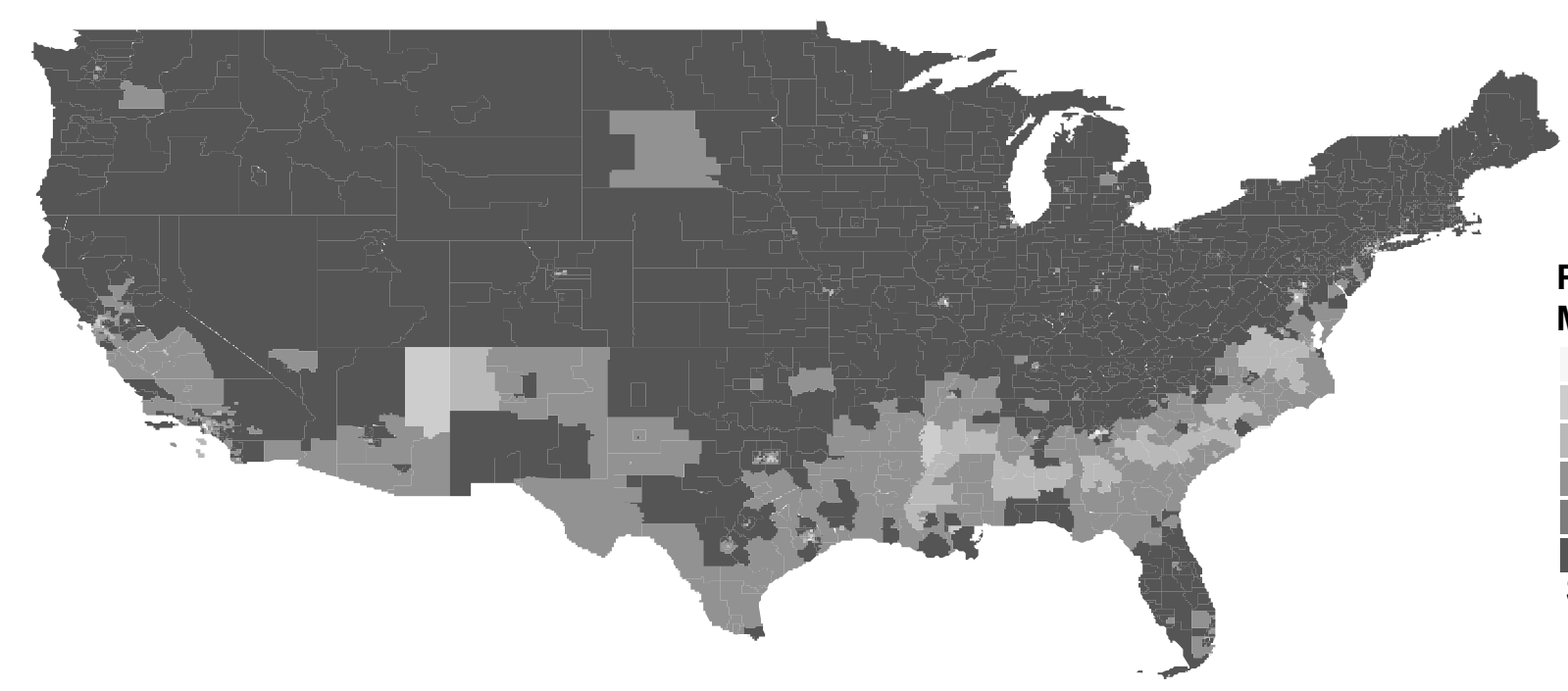

Percent PUMA White Relative to Mean Across All PUMAS $>3$ Std. Dev. Below Mean 2 - 3 Std. Dev. Below Mean 1 - 2 Std. Dev. Below Mean 0 - 1 Std. Dev. Below Mean National Mean

0 - 1 Std. Dev. Above Mean Source: 1990 Census (STF3) 


\section{Percent PUMA Black}

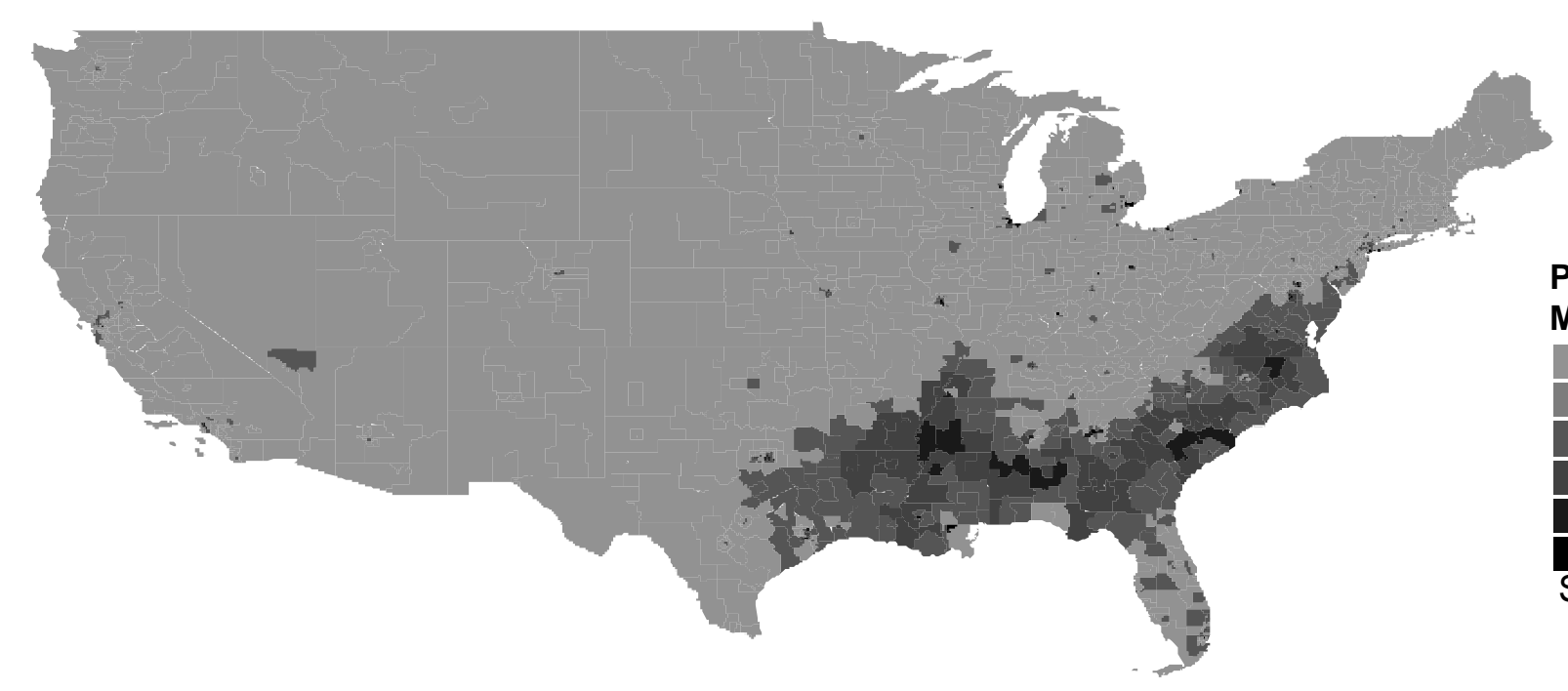

Percent PUMA Black Relative to Mean Across All PUMAS

0 - 1 Std. Dev. Below Mean National Mean

0 - 1 Std. Dev. Above Mean

1 - 2 Std. Dev. Above Mean

2 - 3 Std. Dev. Above Mean $>3$ Std. Dev. Above Mean Source: 1990 Census (STF3) 


\section{Percent PUMA Asian}

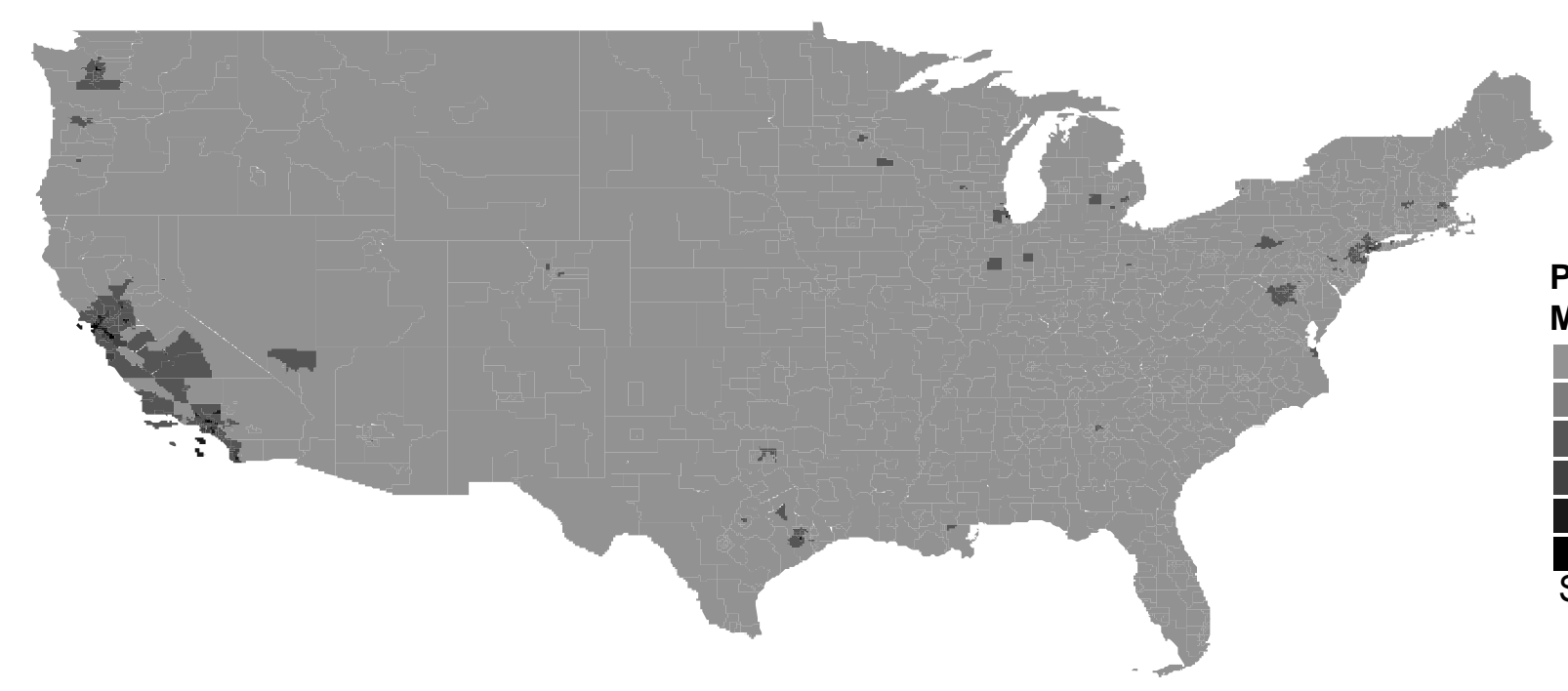

Percent PUMA Asian Relative to Mean Across All PUMAS

0 - 1 Std. Dev. Below Mean

National Mean

0 - 1 Std. Dev. Above Mean

1 - 2 Std. Dev. Above Mean

2 - 3 Std. Dev. Above Mean

$>3$ Std. Dev. Above Mean

Source: 1990 Census (STF3) 


\section{Percent PUMA Hispanic}

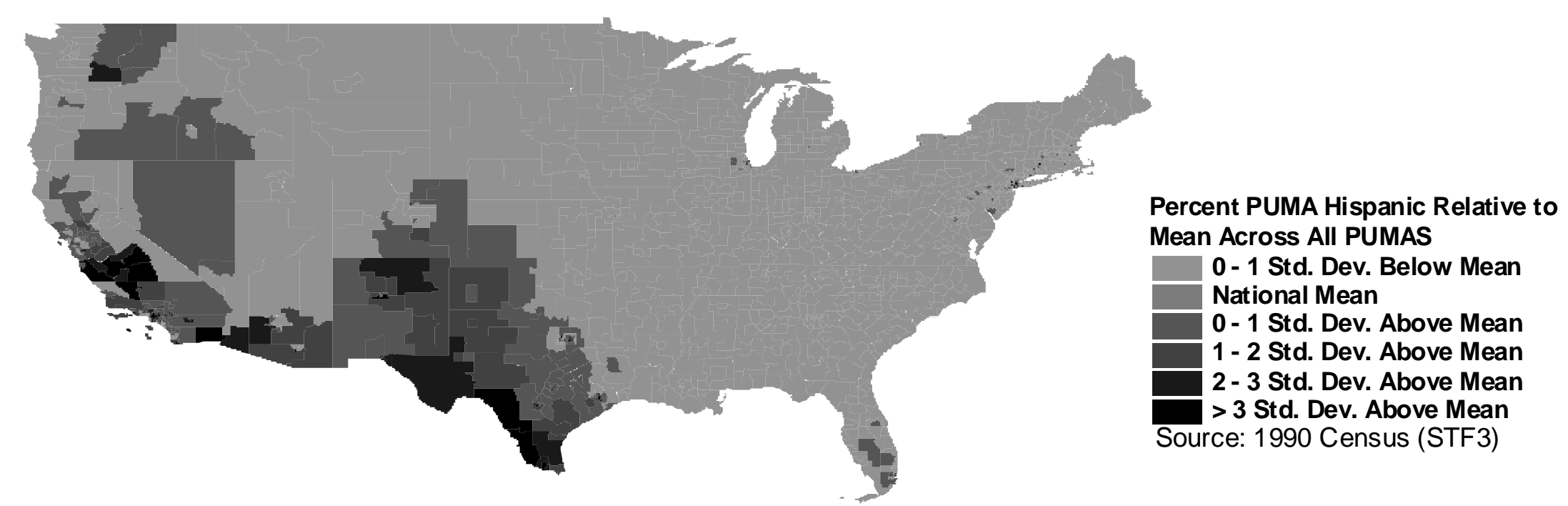

